\title{
1 Bacterial Cellulose Films: Influence of bacterial strain and \\ 2 drying route on film properties
}

3 Muling Zeng, Anna. Laromaine*, Anna Roig

4 Institut Ciència de Materials de Barcelona, Campus UAB, 08193 Bellaterra, Spain.

5 E-mail: alaromaine@icmab.es

6

7 Keywords: bacterial cellulose, films, transparent, bacterial strain, water adsorbent

9 Abstract

Bacterial cellulose is increasingly used as reinforcing material or scaffolds for smart electronics or biomedical applications due to its multifaceted advantages like natural abundance, eco-friendliness, cost-effectiveness, biocompatibility and easy chemical modification. Structural and functional properties of bacterial cellulose depend on the microstructure of the material, which in turn is influenced by the cellulose's origin. This paper reports the production of bacterial cellulose thin films from two bacterial strains, Gluconacetobacter Xylinus and Gluconacetobacter Europaeus, and three methods of drying the thin films; at room temperature, freeze drying and supercritical drying. We have undertaken for the first time a comparative study of how several material's properties such as porosity, transparency, water absorption capacity and mechanical properties are or not affected, and thus can be tuned to some extent, by selecting the bacterial strain or the drying method. For instance, using supercritical drying, we obtained mechanically robust and extremely light films with up to $96 \%$ of porosity, and with a water absorption capacity up 110 times their dried weight. Finally, we suggest the appropriate choice of strains and drying methods for different applications, for instance to obtain cellulose composites with high efficiency in the loading of the components. 


\section{Introduction}

The interest in cellulose and cellulose composites materials have recently expand due to their sustainable and environmentally friendly sources (vegetable or bacterial), their functional and structural properties and applications.(Hu et al. 2014) Its facile derivatization and formulations yields organic-inorganic cellulose composites materials which usually as films find application in oil and water absorbents,(Sai et al. 2013; Nata et al. 2011; Ul-Islam et al. 2012b; Jin et al. 2011) organic light emitting diodes, (Ummartyotin et al. 2012) flexible and transparent electronics(Wicklein and Salazar-Alvarez 2013) to name a few.(Klemm et al. 2011)

Vegetal cellulose is extracted from plants and wood and bacterial cellulose (BC) is produced by microbial fermentation. Although with higher production cost than vegetal cellulose, BC offers a pure biopolymer that exhibits a higher degree of polymerization and better crystallinity than plant’s cellulose.(Ross et al. 1991 ) They exhibit high water content, high elasticity and mechanical stability. Importantly, BC does not contain lignin, hemicelluloses and pectin, non-degradable molecules, associated to the toxicity of celluloses.(Ul-Islam et al. 2012a; Czaja et al. 2007) Therefore, BC composites not only find application in electronics or optics but also in the food industry(Shi et al. 2014) (calorie-free dessert)(Kalia et al. 2011) and in medical fields (tissue engineering,(Svensson et al. 2005; Andrade et al. 2013; Saska et al. 2012) and wound healing patches(Ul-Islam et al. 2012a; Fu et al. 2013)).

The blending of components to form cellulose composites although it is simple, offers a poor control of the mixture's homogeneity decreasing the performance of cellulose composites. In order to fabricate homogeneous cellulose composites with high loading of components, researchers take advantage of the high adsorption capability and structural properties of the cellulose fibers. The cellulose origin and processing treatment strongly influence the final characteristics of the composites.(Pinto et al. 2012) 
In order to improve the BC films adsorption capabilities and porosity, we dried the harvested BC thin films using three different methods, room temperature (RD), freeze drying (FD) and using $\mathrm{CO}_{2}$ supercritical (SCD) without any further mechanical treatments to the cellulose fibers. We obtained a plethora of materials with different adsorption capabilities and improved structural properties with few fabrication steps. The selected physical processes evaporate the solvent content within the film, while minimizing hornification processes of the cellulose fibers. When drying at room temperature (RD), capillary pressures of the water meniscus exert a compressive force in the pores of the films that may induce the modification of the structure, density and porosity of BC films. Freeze drying (FD) process dries the film through sublimation of solid water after the BC films have been plunge-freezed in liquid nitrogen. Supercritical drying (SCD) involves the exchange of the water solvent within the BC film by ethanol, a final exchange with liquid $\mathrm{CO}_{2}$ in the reactor and the final evacuation of the $\mathrm{CO}_{2}$ in supercritical phase. Evacuation of solvents in supercritical conditions is commonly used to produce aerogels which is a term given to open pore materials presenting low density and large specific surface area. The most known aerogels are silica,(Murillo-Cremaes et al. 2010; Moner-Girona et al. 2003; Martin et al. 2008; Budunoglu et al. 2011) carbon,(Wu et al. 2013; Mecklenburg et al. 2012) organic-inorganic aerogels(Hendel et al. 2013; Ennajih et al. 2012) and more recently thick pieces of BC aerogels have also been reported (Hendel et al. 2013; Liebner et al. 2010; Cai et al. 2008; Russler et al. 2012).

Additionally, we compared the drying methods along with the BC films produced from two bacterial strains, Gluconacetobacter Xylinus (GX) and Gluconacetobacter Europaeus (GE), to evaluate the impact of the bacterial origin. Gluconacetobacter Xylinus is the most extended bacteria used to produce cellulose, some reports justifies its commercial interest due to the fast cellulose production speed. Gluconacetobacter Europaeus (formerly Acetobacter Europaeus) is one of the most prominent acid acetobacter bacteria species isolated from 
industrial submerged vinegar fermenters with high resistance to acetic acid and it is much less studied for cellulose production that the GX counterpart.(Andrés Barrao et al. 2011)

We compared the microstructure, water holding capacity, transparency and mechanical properties of BC films of less than $100 \mu \mathrm{m}$ in thickness, and produced by two bacterial strains.

Experimental Section

Bacterial strains Gluconacetobacter Xylinum (GX) (ATCC 11142)(Yamada et al. 1997) and Gluconacetobacter Europeaus (GE) (MF03)(Yamada et al. 1997) were purchased from CECT (Spain).

Glucose, peptone, yeast extract and agar were purchased from Conda Lab, and the $\mathrm{NaOH}$, $\mathrm{Na}_{2} \mathrm{HPO}_{4} \bullet 12 \mathrm{H}_{2} \mathrm{O}$ and citric acid monohydrate were bought from Sigma Aldrich and used as received. (1)

\section{Synthesis of BC}

GX and GE were grown on a solid agar and a single colony was expanded in liquid media for

3 days. Then, $8 \mathrm{ml}$ solution was transferred to an Erlenmeyer of $1 \mathrm{~L}$ with $200 \mathrm{~mL}$ of liquid

media. A thin film of bacterial cellulose grew on top of the liquid media over 5 days for GX and 10 days for GE. Culture media for GX consisted of 20 g/L glucose, 5 g/L peptone, 5 g/L yeast extract, $1.15 \mathrm{~g} / \mathrm{L}$ citric acid monohydrate and $6.8 \mathrm{~g} / \mathrm{L} \mathrm{Na}_{2} \mathrm{HPO}_{4} \bullet 12 \mathrm{H}_{2} \mathrm{O}$. Culture media 5 for GE was composed of glucose $50 \mathrm{~g} / \mathrm{L}$ and yeast extract $10 \mathrm{~g} / \mathrm{L}$.(Liebner et al. 2010; Kim et al. 2010; S. Hestrin 1954)

7 BC films harvested from the air/liquid interface were immersed in ethanol. Subsequently they 8 were transferred to deionized (DI) water and boiled for $40 \mathrm{~min}$, four times more with $0.1 \mathrm{M}$ $\mathrm{NaOH}$ at $90{ }^{\circ} \mathrm{C}$ for 20 min and finally, neutralized with DI water for $24 \mathrm{~h}$. 


\section{Drying methodologies}

103 Never dried Bacterial cellulose (BC) films were cut into a rectangular shapes of 1 x $2 \mathrm{~cm}$.

104 Before drying, samples were placed over a sheet of chromatography paper and kept between

105 two glass slides during the drying process. We created an accordion-like setup for each drying 106 methodology, up to 10 BC films were placed in the same setup. BC fibers were not

107 mechanically modified and the BC film maintains the shape from the bacterial culture. Figure 108 S1 presents schematics and pictures of the drying setup.

109

\section{Room temperature drying method (RD)}

111 BC films placed in the accordion setup were kept at room temperature for 4 days until the BC

112 films were completely dried.

\section{Freeze-drying method (FD)}

114 We plunge-freezed the samples in the accordion setup with liquid nitrogen for 5 min in a 50 $\mathrm{mL}$ falcon tube. After, they were placed in the freeze-drier for $12 \mathrm{~h}$. Freeze-drying of the samples was performed with a LYOQUEST-85 freeze drier (Telstar) at $-80^{\circ} \mathrm{C}$, below 0.005

\section{7 mbar for $12 \mathrm{~h}$.}

\section{Supercritical $\mathrm{CO}_{2}$ drying method (SCD)}

119 BC films were subjected to a solvent exchange step, which was performed by gently shaking

120 them in absolute ethanol. After 6 and $12 \mathrm{~h}$, the gels were transferred two times to a fresh

121 ethanol bath without shaking. After another $6 \mathrm{~h}$ in ethanol, the resulting alcogels were dried.

122 Supercritical process was performed on SCF $300 \mathrm{ml}$ Plant in MATGAS, Spain. Alcogels BC

123 films were placed in the accordion setup and loaded into a $300 \mathrm{ml}$ autoclave vessel filled with

124 ethanol. The autoclave was pressurized to 100 bar at room temperature. We exchanged the

125 ethanol with liquid $\mathrm{CO}_{2}$ flowing at $1 \mathrm{~kg} / \mathrm{h}$ for $1.5 \mathrm{~h}$. We heated the reactor at $45^{\circ} \mathrm{C}$; with a

$126 \mathrm{CO}_{2}$ flow of $1 \mathrm{~kg} / \mathrm{h}$ for $1 \mathrm{~h}$ (these are the SCD conditions, $45^{\circ} \mathrm{C}, 100 \mathrm{bar}$ ). After the drying

127 period, we slowly depressurized the autoclave and removed the dry aerogels. 


\section{Characterization of BC films}

130 Fourier Transform Infra-Red Spectroscopy with Attenuated Total Reflectance (FTIR131 ATR)

132 We folded 5 times the BC films and placed them onto the Universal diamond ATR top-plate

133 (Perkin Elmer). IR spectra were acquired using a PerkinElmer FT-IR Spectrum One with U-

134 ATR at $4 \mathrm{~cm}^{-1}$ resolution, between 4000 to $500 \mathrm{~cm}^{-1}$ using 4 scans and a pressure force

135 between $80 \%$ and $90 \%$.

136 X-Ray Diffraction (XRD)

137 XRD patterns of the BC films were recorded using an X-Ray Diffractometer (Siemens, Model

138 D-5000), using a $\mathrm{Cu}$ anode with $\lambda_{\mathrm{K} \alpha 1}=1.540560 \AA$ and $\lambda_{\mathrm{K} \alpha 2}=1.544390 \AA$ in the $2 \theta$ range of 3

$139-60^{\circ}$ using a step of $0.02 \% \mathrm{~min}$. All samples were fixed flat on a silicon wafer to perform the 140 measurement.

141 We calculated the crystallinity of BC films using the height of peaks (CrI)(Segal et al. 1959;

142 Wang et al. 2008) computed them using Spectrum Viewer Basic 2.6. The height of the peak at 143 (200) represents the crystalline part $I_{(200)}$ and the minimum height between (200) and (110)

144 peaks the amorphous part, $I_{(a m)}$. We also used the same equation 1 but instead of the height of

145 the peaks, we used the area, and we obtained the same results. (Table S1)

146 Equation 1

$$
\mathrm{CrI}=\left(I_{(200)}-I_{(a m)}\right) / I_{(200)}
$$

147 The crystal size using the (200) peak was computed using Scherrer's equation:(Mansikkamaki 148 et al. 2007; Zhang et al. 2001)

149 Equation 2

$$
\mathrm{L}(\mathrm{h} \mathrm{k} \mathrm{l})=\mathrm{k} \lambda /(\mathrm{B} \cos \Theta)
$$

150 Where $\mathrm{L}$ is the crystallite domain, $\lambda$ is the $\mathrm{X}$-ray wavelength, $\Theta$ is diffraction angle in radians

151 and $\mathrm{B}$ is the full width at half maximum of peak $\left(\mathrm{B}^{2}=\mathrm{B}_{\text {total }}{ }^{2}-\mathrm{B}_{\text {instrument }}{ }^{2}\right), \mathrm{B}_{\text {total }}$ is the integral

152 breadth in radians of diffraction angle and $\mathrm{B}_{\text {instrument }}$ is the instrumental integral breadth in

153 radians and $\mathrm{k}$ (Scherrer's constant) is a dimensionless shape factor. The shape factor has a 
154 typical value of about 0.9 , but varies with the actual shape of the crystal, $\mathrm{k}=0.94$ was chosen

155 in our case. (Das et al. 2010; Dietrich et al. 1987)

156

\section{Scanning Electron Microscopy (SEM)}

158

159

160

161

162

163

164

165

166

167

168

169

170

171

172

173

174

175

176

177

178

179

All BC film samples were gold coated for $1 \mathrm{~min}$ at $20 \mathrm{~mA}$, approximately with $1 \mathrm{~nm}$ of gold with a K550 Sputter Coater (Coating Attachment Emitech. Ashford, UK). Samples were placed on a SEM aluminum substrate over a carbon tape adhesive. Images of Scanning Electron Microscopy (QUANTA FEI 200 FEG-ESEM ) were taken at high vacuum conditions, an acceleration voltage of $10-30 \mathrm{kV}$, an electron beam spot of 2.5 , a pressure of 2 to $8 \times 10^{-4} \mathrm{~Pa}$ and a distance of $2-6 \mathrm{~mm}$. SEM images of BCE-RD samples were acquired at the low vacuum conditions, an acceleration voltage of $10 \mathrm{kV}$, an electron beam spot of 2.5, a pressure of $40 \mathrm{~Pa}$ and a distance of $5 \mathrm{~mm}$ to improve the image acquisition.

Thickness of the films were computed using an optical microscope in differential interference contrast mode ( $\mathrm{n}=10)$ (Olympus IX-71, program of Stream Essential 1.7).

\section{Thermal Gravimetric Analysis (TGA)}

Thermal gravimetric analysis of the BC films was performed with a TGA-DSC/DTA analyzer (NETZSCH STA 449 F1 Jupiter, ICMAB) with a heating rate $20^{\circ} \mathrm{C} / \mathrm{min}$ from room temperature to $800{ }^{\circ} \mathrm{C}$ in air.

\section{Water Absorption Capacity (WAC)}

BC films grown for 10 days were dried and weighted. We immersed them in DI water for $1 \mathrm{~h}$, $2 \mathrm{~h}$ and 2 days. Excess water was removed at each time and measured the weight again. The water absorption capacity was defined by:

Equation 3

$$
\mathrm{W}=\left(\mathrm{W}_{\text {wet }}-\mathrm{W}_{\mathrm{o}}\right) / \mathrm{W}_{\mathrm{o}}
$$


$\mathrm{W}_{\text {wet }}$ (weight of wet BC films), $\mathrm{W}_{\mathrm{o}}$ (initial weight of the dried BC films).

181

182

183

184

185

186

187

188

189

190

191

192

193

194

195

196

197

198

199

\section{Optical transmittance}

The optical transmittance of the films was measured using an ultraviolet-visible (Uv-vis) spectroscopy (Shimadzu UV/VIS UV-2102 spectrometer) in the $250 \mathrm{~nm}$ to $800 \mathrm{~nm}$ range. Samples were carefully cut into the rectangle shapes as one side of the cuvette; they were placed in the front side of the Uv-vis spectroscopy cuvette in order to take the spectrum.

\section{Mechanical properties}

Penetration depth at maximum load $(0.4 \mathrm{mN})$, Hardness, Young's modulus and Elastic parameter (EP\%) of BC films were obtained with a nanoindenter (Nanoindenter XP system) with a Berkovich diamond indentation tip. All samples were cut into 0.5 x $1 \mathrm{~cm}$ and were fixed flat on the holder using double-sided tape, without any further preparation. Indentation curves were obtained at a loading and unloading rate of $0.08 \mathrm{mN} / \mathrm{s}$ and maximum load of 0.4 $\mathrm{mN}$. BC films were measured 5-10 times in regions separated within $5 \mu \mathrm{m}$ each measurement in order to evaluate and average the whole surface. Two different BC films samples were evaluated for each type of material.

EP parameter was computed with:

Equation 4: EP \%= (penetration depth at max loading - penetration depth after unloading)/ (penetration at max loading) \%.

\section{Evaluation of mechanical properties and directionality of fibers}

BC-SCD films $(1 \times 2 \mathrm{~cm})$ were cut into 2 smaller pieces $(1 \times 1 \mathrm{~cm})$. One was fixed flat on the holder by double-sided tape; another piece was turned $90^{\circ}$ and then fixed on the same holder. Pieces were tested with the same setup conditions by Nanoindenter XP system. 


\section{Results and discussion}

\section{Production of thin BC films}

209 Two bacterial gram-negative strains, Gluconacetobacter Xylinum (GX) and

210 Gluconacetobacter Europeaus (GE) produced thin films of bacterial cellulose (BC). First,

211 harvesting times of the two strains were adjusted to obtain similar film thicknesses. 10 days of

212 culture for GE and 5 days for GX yielded BCE and BCX films of comparable thicknesses at

213 the top of the culture liquid media of an erlenmeyer at $25^{\circ} \mathrm{C}$, Figure $1 \mathrm{~A}$. Prior to films drying,

214 BC layers were cleaned to remove any bacterial detritus following a previously reported alkali

215 procedure.(Liebner et al. 2010; George et al. 2008) After the alkali treatment, BC films

216 increased their transparency, Figure 1B.

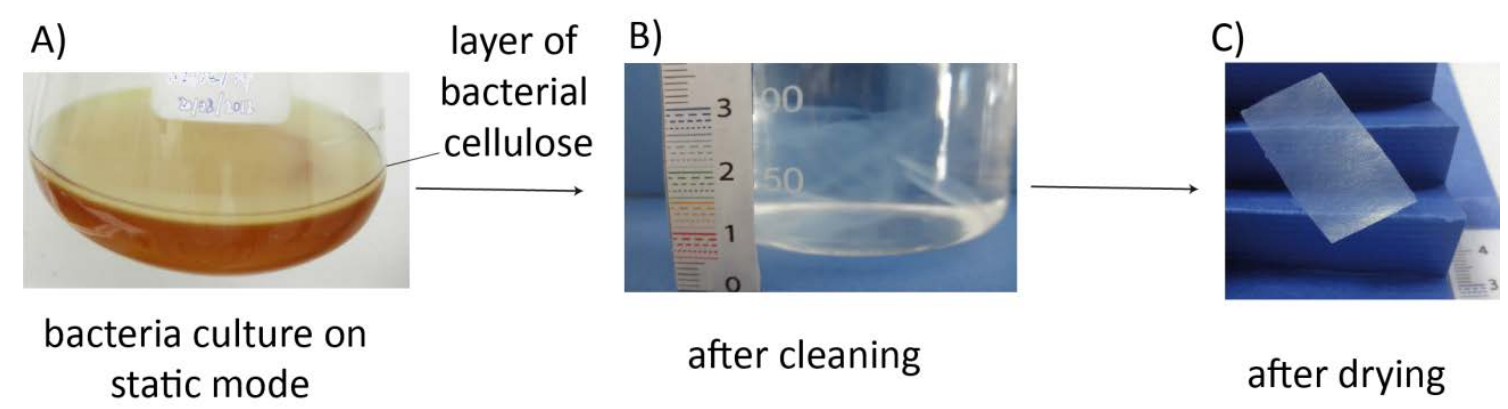

218 Figure 1. (A) Picture of a BC layer on top of the bacteria culture liquid media. (B)

Cleaned BC films obtained after the NaOH treatment. (C) Picture show a final BC film

dried and the accordion setup were $\mathrm{BC}$ films are held during the drying process.

Films were then dried using three methods: a) solvent evaporation at room temperature (RD),

b) freeze drying (FD) and c) using supercritical $\mathrm{CO}_{2}$ (SCD). In all cases, wet films were

224 placed in a home-made holder. A paper accordion construct held BC films in between two glass slides to ensure regular shapes and prevent bending during drying, Figure S1. This design afforded flat and thin films of less than $100 \mu \mathrm{m}$ in thickness, Figure 1C, with few steps

227 and different properties. 


\section{Characterization}

230 BC films are a semi crystalline material and produce broad diffraction peaks. Figure 2A 231 shows the XRD patterns of BCE films treated with different drying methods. Native cellulose 232 is present in two different crystalline cellulose I modifications ( $\mathrm{I}_{\alpha}$ and $\left.\mathrm{I}_{\beta}\right)$, which can be found 233 alongside each other at $2 \Theta=14.24$ and 17.36 corresponding to $<1-10>,<110>$ respectively, 234 the $I_{\alpha} / I_{\beta}$ ratio depends on the origin and the processing of the cellulose. (Klemm et al. 2005; 235 Atalla and Vanderhart 1984) After the alkali treatment, all BC films showed two main peaks at $2 \Theta=14.6$ and 22.6 arising from crystalline planes $<1-10>$ and $<200>$, respectively, and BCE-SCD also showed a small peak at $\sim 17.1^{\circ}(2 \Theta)$ arising from the $<110>$ plane. Relative crystallinity (CrI) of BCE-SCD, BCE-FD and BCE-RD films was calculated using

239 the intensity of the $<200>$ peak considering equation 1 and yielding $82.9 \%, 75.6 \%$ and $24072.5 \%$, respectively. In addition to the highest crystallinity observed for the BCE-SCD films, 241 those also present a slightly smaller crystalline domain (15 nm) as compared to FD (16 nm) 242 and RD (17 nm). Since all BC films derive from the same initial sample, any variations in the 243 crystallinity and crystal size are caused by the drying methods. The higher temperature of the 244 drying with SCD, $45^{\circ} \mathrm{C}$, could afford this small increase of cristallinity. We obtained the same 245 patterns for BCX films, indicating that the cristallinity of the cellulose fibers are independent 246 of the bacterial strain.

248 The IR spectrum of the BC films are characterized by a strong and broad band around $v(\mathrm{CH})$ $249(\mathrm{OH}): 3342,3347 \mathrm{~cm}^{-1}$ corresponding to the overlap of the stretching vibrations of C-H and O$250 \mathrm{H}$ respectively and a strong peak at $v\left(\mathrm{CH}_{2}\right.$ and $\left.\mathrm{CH}\right)$ around $2895 \mathrm{~cm}^{-1}$. Cleanliness of the 251 materials can be monitored by the decrease of the amide I ( $v$ (strong) $)_{\mathrm{C}=\mathrm{O}}$ : $1642 \mathrm{~cm}^{-1}$ ) peak, 252 Figure 2B.(Klemm et al. 2001) 

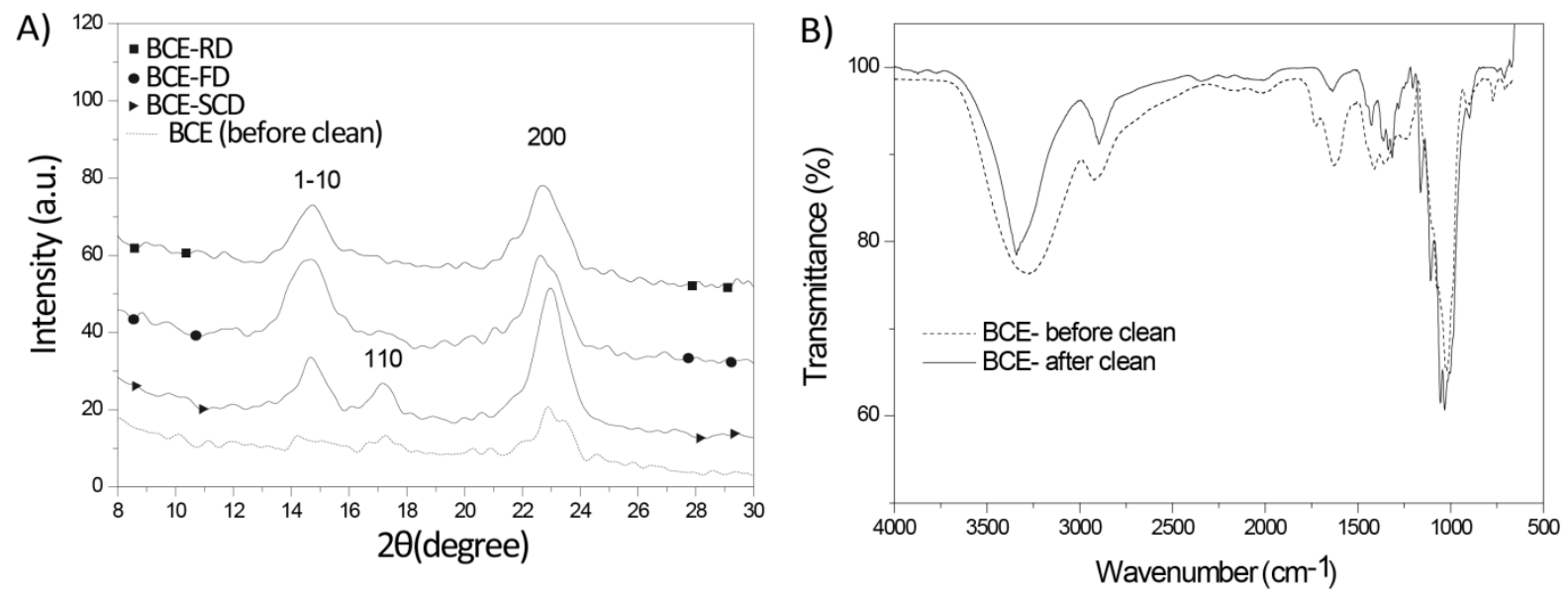

254 Figure 2. (A) X-ray diffraction pattern for BCE- RD, BCE- FD, BCE- SCD and non cleaned BCE film. (B) FTIR spectra for a non-cleaned BCE film and a BCE film after cleaning.

Thermogravimetric analysis of BC films showed the typical single step thermal degradation profile with a decomposition temperature around $350{ }^{\circ} \mathrm{C}$, Figure S2. The residual mass of BC films is less than $4 \%$ indicating BC films were free of impurities. These values agree to previously TGA analysis reported for BC materials after alkali treatment. (George and Ramana 2005)

The thickness and size of wet and dry films were measured using an optical microscope in differential interference contrast microscopy mode. Table 1 summarizes the film thicknesses of the dried films $(n=10)$. For both strains, films dried in SCD conditions are thicker than films obtained by FD and RD. The elimination of the solvent meniscus during supercritical solvent evacuation, avoids the effects of the capillary forces, as described previously for other aerogel materials. The initial thickness of the wet BC films were around $200 \mu \mathrm{m}$ and after drying the computed thickness of all BC films decreased, ranging from $67 \mu \mathrm{m}$ to $24 \mu \mathrm{m}$.

Density values $(\rho)$ were determined from weighting the materials and measuring the BC films' 
$273 \mathrm{~g} / \mathrm{cm}^{3}$ showing only a slight dependency of the density with the drying method but strong

274 influence of the bacterial source. Densities of the BCX films are in the $0.16-0.6 \mathrm{~g} / \mathrm{cm}^{3}$ range

275 and they strongly depend on the drying method used. BCX films dried by SCD are lighter

276 than FD and RD ( $\left.\rho_{\mathrm{BCX}-\mathrm{RD}}>\rho_{\mathrm{BCX}-\mathrm{FD}}>\rho_{\mathrm{BCX}-\mathrm{SCD}}\right)$, although they are still two times denser than

277 any BCE film $\left(\rho_{\mathrm{BCX}}>\rho_{\mathrm{BCE}}\right)$, see Table 1.

278 From the density values one can evaluate the total porosity of the films from the equation:

279 Total porosity $(\phi)=1-\left(\rho_{\mathrm{BC}}\right.$ film $\left./ \rho_{\text {cellulose }}\right)$; where we have assumed a $\rho_{\text {cellulose }}=1.5 \mathrm{~g} / \mathrm{cm}^{3}$

280 (Mwaikambo and Ansell 2001; Sehaqui et al. 2011; Sun 2005) for both strains. Following the same trend as for the

281 density, we observed that BCE films have a porosity larger than $94 \%$ for the three drying

282 methods. On the other hand, BCX films are less porous and their porosity strongly depends on

283 the drying method used. We believe that the slow formation of the cellulose fibrils in GE

284 influences the microstructure of the film, forming fibrils more resistant to compact and finally

285 affording a more spongy structure.(Mwaikambo and Ansell 2001; Sehaqui et al. 2011; Sun

286 2005).The porosity, density are strongly affected by the bacterial strain and the drying

287 methods.

289 Microstructure of the BC film

290 BC films present an open porous network of cellulose fibers confirmed by scanning electron microscopy (SEM), Figure 3. Similarly to previous reports,(Siro and Plackett 2010; Schutz et al. 2012) BC films show a hierarchical structure with pores of different sizes from macro to micro. For both strains, SCD drying method offer the most open structure and a higher presence of individual fibrils than FD and RD films. BET measurements of the porosity of the 295 thin films provided partial results of the porosity of the thin BC films skewed towards the mesoscale.

297 Individual cellulose fibrils measured by SEM are approximately $18 \pm 2 \mathrm{~nm}$ in thickness 298 independently of the strain and the drying method used. Thus, the strain used or the drying 
methods do not seem to influence the fibril size which is somehow surprising considering the

300 difference in the cellulose growth rate of the two strains. In contrast, a detailed observation of

301 the images showed that the drying method impact the fiber entangling. Analyzing in detail

302 several SEM images, we computed that for both strains, $85 \pm 2 \%$ of the fibers form bundles

303 in the films dried at RD and FD whereas we detect just a $38 \pm 2 \%$ of the fibers forming

304 bundles in SCD films. Moreover, BCX-SCD is the material with the most differentiated

305 microstructure since we distinguish higher number of individual fibers, less entanglement and

306 some degree of directionality of the fibers in comparison to the rest of the films. Some

307 detailed studies to elucidate if fiber directionality induces anisotropic mechanical behavior

308 will be analyzed.
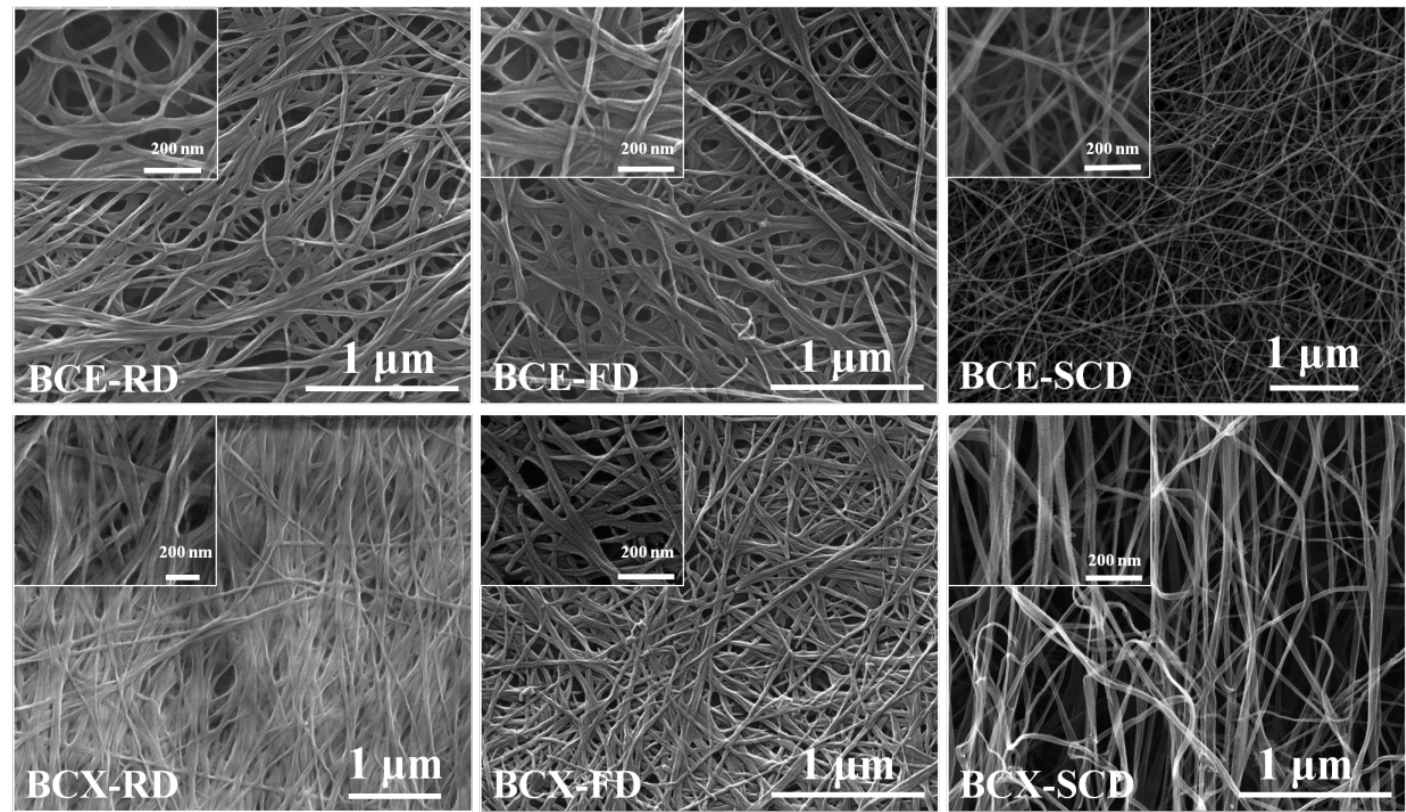

310

311 Figure 3. SEM images of the BC films obtained after different drying conditions. Inserts 312 show higher magnification images of the films.

313

\begin{tabular}{|c|c|c|c|c|c|c|c|}
\hline & Drying method & \multicolumn{2}{|c|}{ RD } & \multicolumn{2}{|c|}{ FD } & \multicolumn{2}{|c|}{ SCD } \\
\hline & Strain & BCE & $\mathrm{BCX}$ & BCE & BCX & BCE & $\mathrm{BCX}$ \\
\hline \multirow{4}{*}{ 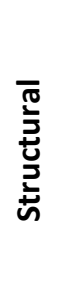 } & $\begin{array}{l}\text { Film Thickness } \\
\qquad(\mu \mathrm{m})\end{array}$ & $24 \pm 2$ & $37 \pm 2$ & $34 \pm 2$ & $40 \pm 4$ & $58 \pm 3$ & $67 \pm 2$ \\
\hline & Density (g/mL) & $0.08 \pm 0.01$ & $0.59 \pm 0.03$ & $0.06 \pm 0.01$ & $0.32 \pm 0.02$ & $0.05 \pm 0.01$ & $\begin{array}{c}0.16 \pm \\
0.01\end{array}$ \\
\hline & $\begin{array}{c}\text { Total Porosity } \\
\text { (\%) }\end{array}$ & $94 \pm 2$ & $60 \pm 2$ & $95 \pm 2$ & $79 \pm 2$ & $96 \pm 2$ & $89 \pm 2$ \\
\hline & Fibers diameter & $17 \pm 2$ & $19 \pm 3$ & $20 \pm 4$ & $19 \pm 3$ & $16 \pm 2$ & $20 \pm 4$ \\
\hline
\end{tabular}




\begin{tabular}{|c|c|c|c|c|c|c|c|c|}
\hline & \multicolumn{2}{|r|}{$(\mathrm{nm})$} & & & & & & \\
\hline & \multirow{3}{*}{$\frac{4}{3}$} & $1^{\text {st }}$ cycle & 39.5 & 37.3 & 15.8 & 15.8 & 109.4 & 66.6 \\
\hline & & $\begin{array}{l}\text { after } 3 \\
\text { cycles }\end{array}$ & 15.3 & 14.2 & 92.3 & 50.2 & 19.8 & 19.4 \\
\hline & & $\begin{array}{c}\text { Decrease } \\
(\%)\end{array}$ & 61 & 62 & 42 & 68 & 82 & 71 \\
\hline \multirow{4}{*}{ 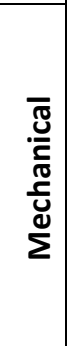 } & \multicolumn{2}{|c|}{$\begin{array}{c}\text { Penetration } \\
\text { depth at } 0.4 \mathrm{mN} \\
\text { load }(\mu \mathrm{m})\end{array}$} & $3.9 \pm 0.4$ & $1.1 \pm 0.1$ & $4.1 \pm 0.4$ & $1.4 \pm 0.3$ & $3.2 \pm 0.5$ & $\begin{array}{c}4.3 \pm \\
1.5\end{array}$ \\
\hline & \multicolumn{2}{|c|}{$\begin{array}{c}\text { Young modulus } \\
(\text { "E")(MPa) }\end{array}$} & $198 \pm 50$ & $659 \pm 90$ & $204 \pm 50$ & $601 \pm 200$ & $238 \pm 20$ & $198 \pm 30$ \\
\hline & \multicolumn{2}{|c|}{$\begin{array}{l}\text { Hardness } \\
\left(“ H^{\prime \prime}\right)(M P a)\end{array}$} & $34 \pm 20$ & $39 \pm 9$ & $20 \pm 8$ & $26 \pm 10$ & $20 \pm 5$ & $19 \pm 20$ \\
\hline & \multicolumn{2}{|c|}{$E P(\%)$} & $59 \pm 7$ & $39 \pm 3$ & $53 \pm 4$ & $33 \pm 3$ & $52 \pm 5$ & $48 \pm 10$ \\
\hline
\end{tabular}

Table 1. Summary of the structural and mechanical values obtained for the BC films.

\section{Water absorption capacity (WAC)}

319 Cellulose materials are good absorbents, this property identifies them as excellent candidates

320 for instance for organic pollutants, absorbents and catalysts (improve efficiency of enzyme

321 loading).(Wu et al. 2013; Shezad et al. 2010) This property is also exploited in order to create

322 cellulose composites with high yield of the different components, for instance in

323 antibactericidal BC patches that need a homogeneous and high loading of Ag

324 nanoparticles.(Ul-Islam et al. 2012a; Ul-Islam et al. 2011) We measured the water absorption

325 capacity and evaluated how the different drying methods and therefore, the microstructure

326 obtained influence the water absorption capacity (WAC). We dried and weighted BC films,

327 upon immersion in distilled water at room temperature for two days they were weighted again.

328 WAC quantifies the percentage of water absorbed in each film. We repeated two times the 329 water absorption cycle drying them at room temperature. The weight of the dry films at the 330 start of each WAC cycles did not change. 

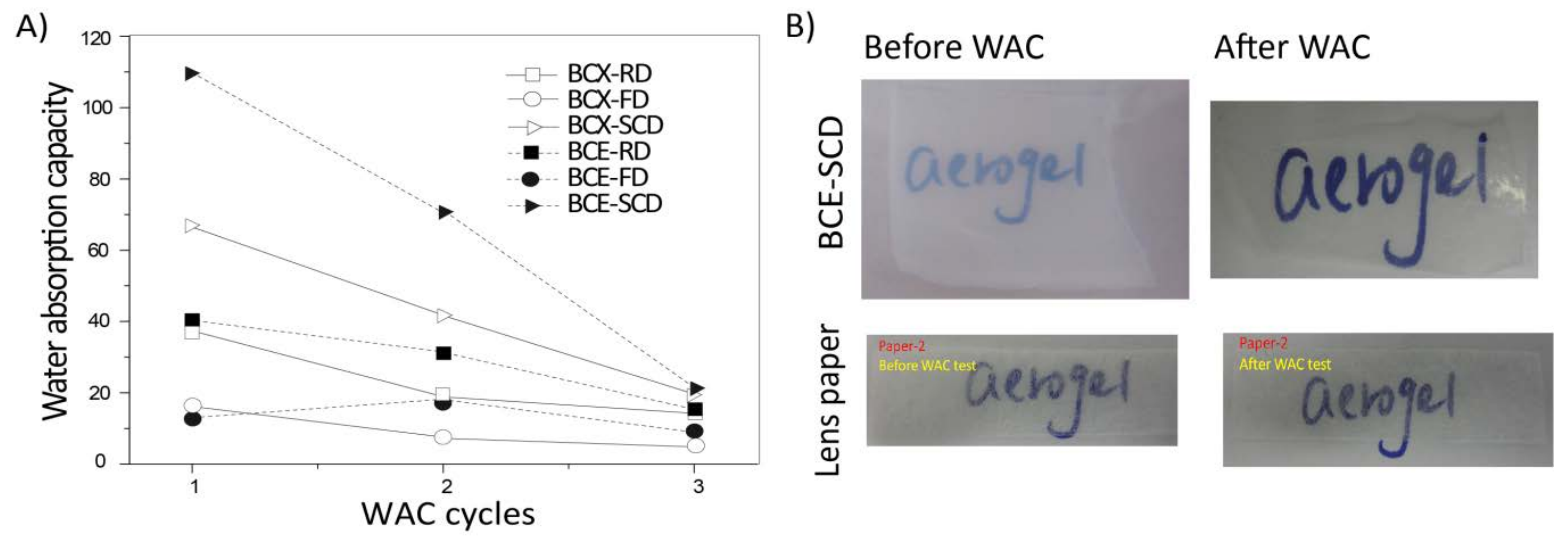

Figure 4. (A) Percentage of the water absorbed in the BC films after three wettingdrying cycles. (B) Images of the BCE-SCD films and lens paper before and after wetting.

WAC shows a strong influence of the drying method used. Supercritically dried films present the highest water absorbance capability of all the films, obtaining water absorption capacities of up to 110 times its own weight for BCE-SCD films, Figure 4A. FD films showed lower water absorption than RD for both strains. SCD drying method emerges as an ideal methodology to improve WAC in native BC films without additional mechanical processes or additives.

The ability of the films to recover the WAC capacity after drying at room temperature was evaluated performing some wetting-drying cycles. After three wetting-drying cycles, the WAC values converged for all the drying methods and the BC films still held up to 20 times

344 their weight of water after 3 cycles, Figure 4A. We hypothesized, since in the WAC cycles we 345 dry the films at room temperature, we compact the tridimensional structure of the film in each 346 cycle until they all become similar. The extraordinary WAC achieved with supercritical 347 drying methods indicates that the structure achieved could afford a methodology to create 348 cellulose composites with high concentration of different compounds in an homogeneous 349 fashion by absorption, such higher and more reproducible absorption of enzymes to improve 350 their response. 
352 Evaluation of the water absorption capacity also revealed that the films increase their

353 transparency upon wetting. Their applications in electronics could also be expanded in water-

354 based applications, for instance in cell-based membranes, in skin-patches with flexible

355 electronics since they could help to monitor wound

356 healing,(http://www.ricoh.com/about/company/technology/tech/033.html) in sensors devices

357 where we could envisage while the liquid is transported without the need of external power,

358 we could image its reactivity from the change in transparency. Pictures depicting the

359 qualitative measurement of the transparency for lens paper, $35 \mu \mathrm{m}$, and the BCE-SCD film

360 before and after WAC cycle are shown in Figure 4B and Figure 5A. (Films are placed in

361 contact with the paper below). BCE-SCD film became more transparent than the lens paper

362 after a WAC cycle, likely related to the collapse of pores in the size range with larger visible

363 wavelengths scattering effect. Pictures of all the films are in Supplementary information

364 Figure S3. Quantification of the transparency using Uv-vis Spectroscopy was performed for

365 BC films. (Figure 5B for BCE and Figure S4 for BCX). BC films do not absorb above $500 \mathrm{~nm}$

366 before and after WAC showing a higher optical transmittance compared to regular

367 chromatography paper of $200 \mu \mathrm{m}$ (Paper 1) and lens paper of $35 \mu \mathrm{m}$ (Paper 2). Initially BCE

368 films are more transparent than BCX films that could indicate the existence of different light

369 scattering effects in the films and they could reveal different surface roughness. (Yano et al.

370 2005) After the different WAC cycles, the optical transmittance improved for all the films.

371 High transparency of BC films at visible wavelengths and the biological origin of the

372 cellulose could appoint this material as a suitable matrix to biological applications where the

373 optical visualization through the material is necessary as for instance in cell culture surfaces. 
A)

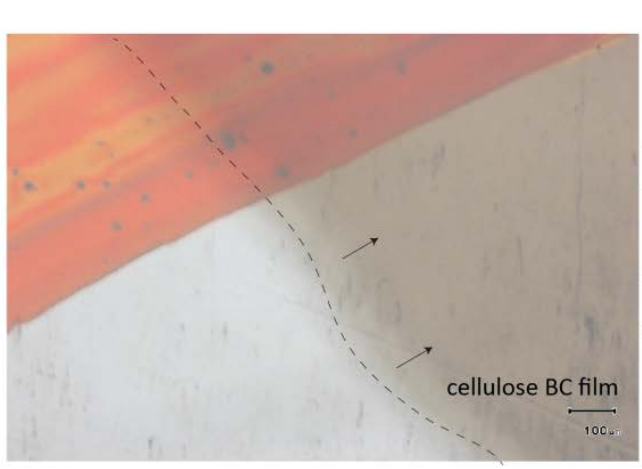

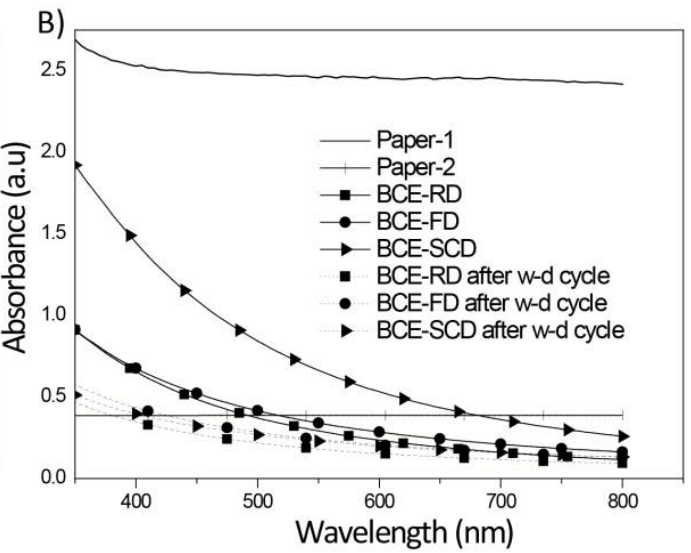

Figure 5. (A) Optical image of the BCE-SCD film immersed in a petri dish with water. The red line on the Petri dish surface is clearly distinguishable through the BC film. (B) Uv-vis spectra of BC films before and after WAC and commercial papers.

\section{Mechanical properties}

Mechanical properties are a key factor for BC films to be used as reinforcing materials, sensors or scaffolds in many applications.(Yano et al. 2005) In particular, for cell studies, the possibility of tuning the mechanical properties of the scaffold for each cell type is very attractive. Biological tissues are soft and elastic and they show a broad range of Young modulus from $1.5 \times 10^{4}-3 \times 10^{4} \mathrm{MPa}$ found in bones to $10^{-4}-10^{-3} \mathrm{MPa}$ in softer tissues such as brain tissue. (Moore et al. 2010) Numerous researchers have revealed that cells have the ability to probe and respond to the rigidity of the substrates they are grown upon.(Pelham and Wang 1997; Rowlands et al. 2008; Engler et al. 2004; Guo et al. 2006) The cellular tensegrity model attempts to suggest that the homeostatic balance of forces governs the reciprocal relationship between cells and the physical properties of their microenvironment.(Cameron et al. 2011)

Firstly, we evaluated qualitatively the elastic behavior of the films by bending them with a tweezers. Figure 6 shows a series of images of the bending test performed. We clearly see that BCE-RD and BCE-FD films fully recovered and a flat sheet was recorded again. SCD films 
did not recover fully and some creased was imaged after bending, although it did not break.

395 After wetting-drying cycles, the BC films do not break, indicating that the films keep their elasticity even after a WAC cycle. Films produced by GX followed the same trend, Figure S5, therefore the bacterial strain do not modify their film's elasticity. Unlike silica aerogels that are brittle and fragile materials, BC aerogels have higher degree of elasticity.(Yano et al. 2005)
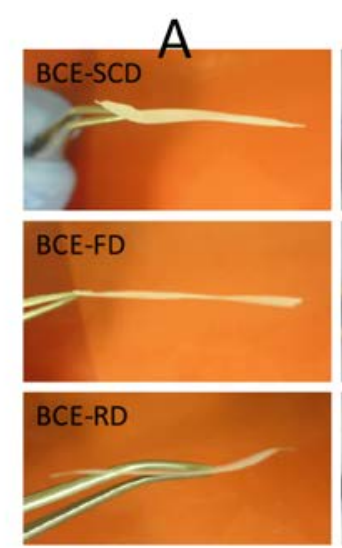
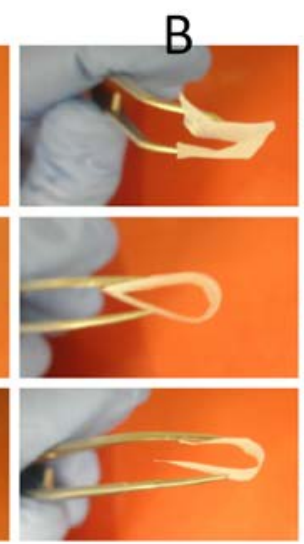

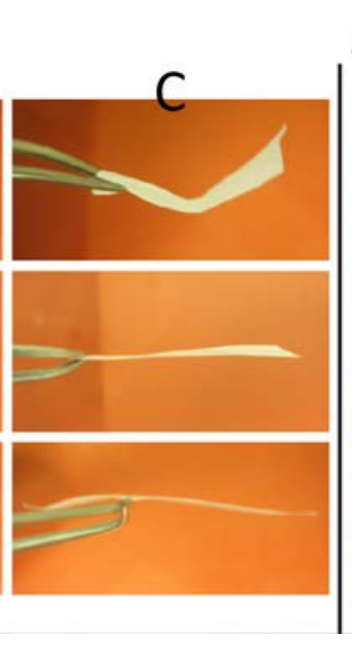

After wetting-drying cycle

Figure 6 Pictures of the bending test performed: (A) BCE films before the bending test

from the different drying methods, $(B)$ process of the bending test, $(C)$ the resulting

shapes of the BC films after the test and (D) the shape of the films obtained on a BCE

film that was wetted-dried (WAC cycle).

To measure the mechanical behavior of the BC films we have used nanoindentation. For the indentation cycles we used a constant maximum load of $0.4 \mathrm{mN}$ to ensure that the penetration depth of the tip into the films was smaller than their thickness. Smaller loads from $0.05-0.1$ $\mathrm{mN}$ did not give us reproducible results. Moreover, we evaluated the effect of the adhesive tape underneath the sample (presence and not presence) and the results did not change, therefore we conclude the adhesive under the sample did not affect the measurements. Figure 7 and Table 1 gather the load-displacement curves and the values obtained for the

412 penetration depth at maximum load, "Young Modulus, E", "Hardness, $H$ " and "elastic parameter, $E P^{\prime \prime}$ for two samples (n=14). The load-displacement curves obtained are 
representative of a material with elastoplastic properties. BC films show similar load-

415 displacement curves except for BCX-RD and BCX-FD that show lower penetration depths 416 and steeper unloading curves.

417 The analysis of the load-displacement curves shows that the BC films have creep and some 418 literature review this property as a very desirable for scaffolds that interact with 419 cells.(Cameron et al. 2011) Although we have use the slope of the curve to calculate the 420 "Young Modulus", ("E") we have to notice that this estimation is not completely correct as the 421 material has a strong elastoplastic behavior, as it happens in soft tissues. The analysis of "E" 422 shows that GE affords less stiff films than GX and they are independent of the drying method, 423 while BCX films are sensitive to the drying method obtaining stiffer BC films if we dry them 424 by RD or FD.

425 The "E" values obtained are around 200 MPa except for BCX-RD and BCX-FD that we 426 observed E of $600 \mathrm{MPa}$, suggesting that their stiffness could be comparable to tissues as bone $427\left(1.5 \times 10^{4}-3 \times 10^{4} \mathrm{MPa}\right)$ and of soft arteries (0.1 - $\left.1 \mathrm{MPa}\right)$.(Moore et al. 2010)
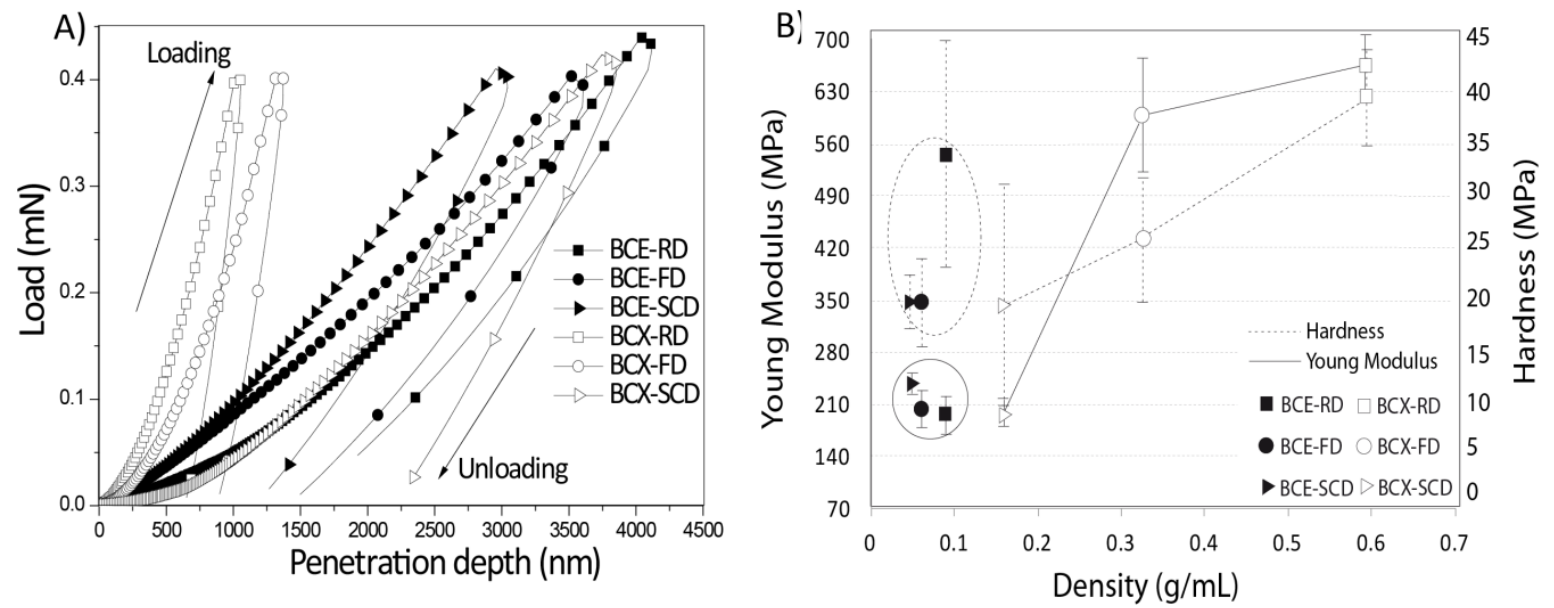

429 Figure 7. (A) Representative loading-unloading curve for each BC film obtained using

430 the nanoindenter under a load of $0.4 \mathrm{mN}$. (B) Mean values of "Young Modulus", ("E") 431 and Hardness (" $H$ ") obtained for each BC film as a function of their density (n=14). We 432 circled the" $E$ "and " $H$ " for BCE for clarity. 
433 The averaged measured Hardness values ("H") of BC samples are around 20 - $34 \mathrm{MPa}$,

434 which indicates the resistance of BC films to the nanoindenter, BC-RD films shows higher

435 " $H$ " values than the others BC films. The elastic component of the BC films was analyzed

436 using the elastic parameter ("EP").(Moner-Girona et al. 1999) BC films presenting large

437 "Young modulus" (BCX-RD and BCX-FD) also exhibit a low elastic character. On the other

438 side, " $E$ " and penetration depth at $0.4 \mathrm{mN}$ values for BCE films are similar to the values found

439 for BCX-SCD film even though they present a much smaller density $\left(0.5-0.8 \mathrm{~g} / \mathrm{cm}^{3}\right.$ for BCE

440 and $0.16 \mathrm{~g} / \mathrm{cm}^{3}$ for BCX-SCD) possibly pointing to a different mechanical strength of the

441 cellulose microfibrils for each strain. The evaluation of the mechanical parameters with the

442 density shows that the combination of BCX and the drying method used allow us to obtain

443 broader range of mechanical properties for BCX films than for the BCE films.

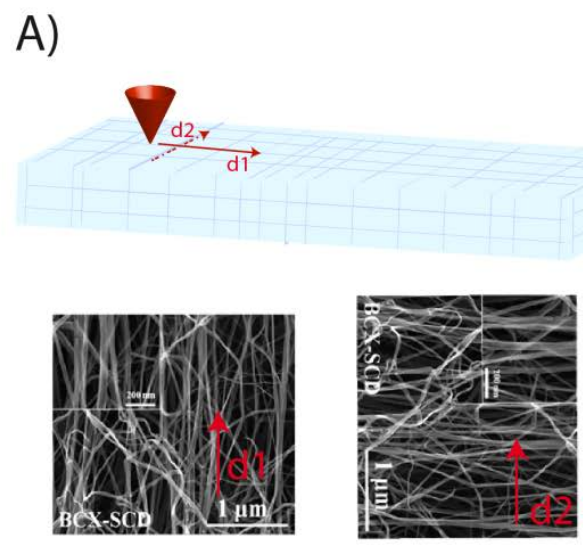

444

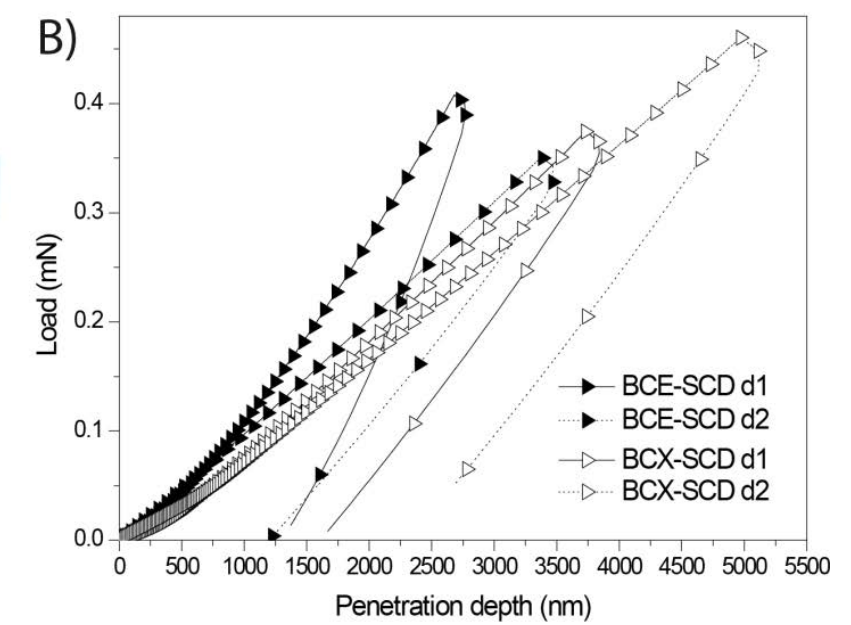

445

Figure 8. A) Schematic representation of the mechanical measurements performed over

two different directions. B) Load- displacement curves for BC films dried on SCD

447

conditions for the two bacterial strains.

448

\begin{tabular}{|c|c|c|c|c|}
\hline & BCE-d1 & BCE-d2 & BCX-d1 & $B C X-d 2$ \\
\hline $\begin{array}{c}\text { "Young modulus, } \\
\text { E" } \mathrm{MPa}\end{array}$ & $233 \pm 50$ & $300 \pm 50$ & $150 \pm 40$ & $242 \pm 100$ \\
\hline $\begin{array}{l}\text { Penetration depth } \\
\text { at } 0.4 \mathrm{mN}(\mu \mathrm{m})\end{array}$ & $3.1 \pm 0.5$ & $3.5 \pm 0.9$ & $4.9 \pm 0.8$ & $4.4 \pm 0.7$ \\
\hline
\end{tabular}



BC films dried in SCD conditions measured in two directions of the BC films.

BC- SCD films show in SEM images some anisotropy, possible directionality of the fibers therefore we evaluated " $E$ " and penetration depth if we placed the sample in two opposite directions. The load-displacement curves show different profiles as a function of the direction of the measurement, Figure 8. The evaluation of " $E$ " of BC-SCD show some anisotropy in the measurements although the penetration depth remains unchanged. We found for BCX-SCD and BCE-SCD a difference in " $E$ " as a function of the direction where we performed the nanoindentation measurements. These results confirm the SEM images that we observed some directionality of the fibers in BCX-SCD; we also found some directionality in BCESCD even though we could not detect it in SEM, Table 2. We believe these are interesting results that recommend a further and deeper analysis of the mechanical properties of the BCSCD films that will be continued with extensive loads, time and different humidity conditions, since BC-SCD films also offer high absorption capacity.

\section{Conclusions}

The use of two strains and three drying methods allowed us to obtain different BC thin films with different structural properties that can improve their application in cellulose composites materials and others. Room temperature drying, freeze-drying, and supercritical drying methods modify the porosity, mechanical properties and water absorption capability of the BC films expanding their range of the properties.

Even after 10 days of culturing, BCE films are more transparent and lighter independently of 472 the drying methods used in comparison to BCX films, harvested for 5 days. BCE-SCD shows 473 the highest water absorbance capacity that allow us to suggest BCE films as suitable candidates for applications such as absorbents, removal of contaminants or wound healing 
SCD film could provide cellulose composites with high loading efficiencies and homogeneous mixtures. Additionally the use of SCD drying improves the cristallinity of the cellulose fibers.

BC films from GX source offer a more versatile platform since we can control the porosity, mechanical properties and water absorption capacity with only one-step, selecting the appropriate drying method. Additionally, GX strain offers the advantage of faster production of BCX films. We hypothesize that these films could be good candidates to interface with tissues since their mechanical properties could be tailored to mimic the final tissue replacement and their mechanical properties are not hampered in aqueous media.

\section{Supporting Information}

Supporting Information is available online or from the author.

\section{Acknowledgements}

The research leading to these results has received funding from the People Program (Marie Curie Actions) of the European Union’s Seventh Framework Program (FP7/2007-2013) under REA grant agreement $n^{\circ} 303630$ and cofounded by the European Social Fund. Authors acknowledge the funding from Spanish Ministry of Economy MAT 2012-35324, COST Action MP1202 and Ramon y Cajal grant RYC-2010-06082 (AL), Chinese Scholarship Council fellowship (MZ). The group of Dr. Alex Peralvarez for their help in the bacterial culture, Dr. Josep PuigMartí and the group of Dr. David Amabilino for the use of the optical microscope, Prof. Elies Molins and Toni Pons for the use and advice in the use of the freeze drier and Dr. Roberto L. Guzman de Villoria for his advices in the mechanical measurements. 
502 Institut Ciència de Materials de Barcelona, Campus UAB, 08193 Bellaterra, Spain.

503

504

505

506

507

508

509

510

511

512

513

514

515

516

517

518

519

520

521

522

523

524

525

526

527

528

529

530

531

532

533

534

535

536

537

538

539

540

541

542

543

544

545

546

547

548

E-mail: alaromaine@icmab.es

Andrade F, Alexandre N, Amorim I, Gartner F, Mauricio A, Luis AL, Gama M (2013) Studies on the biocompatibility of bacterial cellulose. J Bioact Compatible Polym 28 (1):97-112

Andrés Barrao C, Falquet L, Calderon Copete S, Descombes P, Perez R, Ortega Pérez R, Barja F (2011) Genome sequences of the high-acetic acid-resistant bacteria Gluconacetobacter europaeus LMG 18890T and G. europaeus LMG 18494 (reference strains), G. europaeus 5P3, and Gluconacetobacter oboediens 174Bp2 (isolated from vinegar). J Bacteriol 193 (10):2670-2671

Atalla RH, Vanderhart DL (1984) Native Cellulose: A Composite of Two Distinct Crystalline Forms. Science 223 (4633):283-285. doi:10.1126/science.223.4633.283

Budunoglu H, Yildirim A, Guler MO, Bayindir M (2011) Highly Transparent, Flexible, and Thermally Stable Superhydrophobic ORMOSIL Aerogel Thin Films. ACS Appl Mater \& Interf 3 (2):539-545. doi:10.1021/am101116b

Cai J, Kimura S, Wada M, Kuga S, Zhang L (2008) Cellulose aerogels from aqueous alkali hydroxide-urea solution. ChemSusChem 1 (1-2):149-154

Cameron AR, Frith JE, Cooper-White JJ (2011) The influence of substrate creep on mesenchymal stem cell behaviour and phenotype. Biomaterials 32 (26):5979-5993. doi:http://dx.doi.org/10.1016/j.biomaterials.2011.04.003

Czaja WK, Young DJ, Kawecki M, Brown RM (2007) The future prospects of microbial cellulose in biomedical applications. Biomacromolecules 8 (1):1-12. doi:10.1021/bm060620d

Das K, Ray D, Bandyopadhyay NR, Sengupta S (2010) Study of the Properties of Microcrystalline Cellulose Particles from Different Renewable Resources by XRD, FTIR, Nanoindentation, TGA and SEM. J Polym Environ 18 (3):355-363

Dietrich A, Goring DAI, Revol JF (1987) Effect of mercerization on the crystallite size and crystallinity index in cellulose from different sources. Can J Chem 65 (8):1724-1725

Engler A, Bacakova L, Newman C, Hategan A, Griffin M, Discher D (2004) Substrate Compliance versus Ligand Density in Cell on Gel Responses. Biophys J 86 (1):617628. doi:http://dx.doi.org/10.1016/S0006-3495(04)74140-5

Ennajih H, Bouhfid R, Essassi E, Bousmina M, El Kadib A (2012) Chitosan-montmorillonite bio-based aerogel hybrid microspheres. Microporous Mesoporous Mater 152:208-213

Fu L, Zhang J, Yang G (2013) Present status and applications of bacterial cellulose-based materials for skin tissue repair. Carbohydr Polym 92 (2):1432-1442. doi:http://dx.doi.org/10.1016/j.carbpol.2012.10.071

George J, Ramana KV (2005). Int J Biol Mole 37:189

George J, Sajeevkumar VA, Kumar R, Ramana KV, Sabapathy SN, Bawa AS (2008) Enhancement of thermal stability associated with the chemical treatment of bacterial (Gluconacetobacter xylinus) cellulose. J Appl Polym Sci 108 (3):1845-1851. doi:10.1002/app.27802

Guo W-h, Frey MT, Burnham NA, Wang Y-l (2006) Substrate Rigidity Regulates the Formation and Maintenance of Tissues. Biophys J 90 (6):2213-2220

Hendel T, Lesnyak V, Kuhn L, Herrmann AK, Bigall NC, Borchardt L, Kaskel S, Gaponik N, Eychmuller A (2013) Mixed Aerogels from Au and CdTe Nanoparticles. Adv Funct Mater 23 (15):1903-1911. doi:10.1002/adfm.201201674

http://www.ricoh.com/about/company/technology/tech/033.html. 
Hu W, Chen S, Yang J, Li Z, Wang H (2014) Functionalized bacterial cellulose derivatives and nanocomposites. Carbohydr Polym 101:1043-1060. doi:10.1016/j.carbpol.2013.09.102

Jin H, Kettunen M, Laiho A, Pynnonen H, Paltakari J, Marmur A, Ikkala O, Ras RHA (2011) Superhydrophobic and Superoleophobic Nanocellulose Aerogel Membranes as Bioinspired Cargo Carriers on Water and Oil. Langmuir 27 (5):1930-1934. doi:10.1021/la103877r

Kalia S, Kaith BS, Kaur I (2011) Cellulose Fibers: Bio- and Nano-Polymer Composites. Springer, Berlin

Kim S, Kim HJ, Jeon NL (2010) Biological applications of microfluidic gradient devices. Integrative Biol 2 (11-12):584-603. doi:10.1039/c0ib00055h

Klemm D, Heublein B, Fink. HP, Bohn A (2005) Cellulose:Fascinating Biopolymer and Sustainable Raw Material. Angew Chem 44:3358-3393

Klemm D, Kramer F, Moritz S, Lindström T, Ankerfors M, Gray D, Dorris A (2011) Nanocelluloses: A New Family of Nature-Based Materials. Angew Chem Int Ed 50 (24):5438-5466. doi:10.1002/anie.201001273

Klemm D, Schumann D, Udhardt U, Marsch S (2001) Bacterial synthesized cellulose artificial blood vessels for microsurgery. Prog Polym Sci 26:1561-1603

Liebner F, Haimer E, Wendland M, Neouze MA, Schlufter K, Miethe P, Heinze T, Potthast A, Rosenau T (2010) Aerogels from Unaltered Bacterial Cellulose: Application of scCO(2) Drying for the Preparation of Shaped, Ultra-Lightweight Cellulosic Aerogels. Macromol Biosci 10 (4):349-352. doi:10.1002/mabi.200900371

Mansikkamaki P, Lahtinen M, Rissanen K (2007) The conversion from cellulose I to cellulose II in $\mathrm{NaOH}$ mercerization performed in alcohol-water systems: An X-ray powder diffraction study. Carbohydr Polym 68 (1):35-43. doi:10.1016/j.carbpol.2006.07.010

Martin L, Osso JO, Ricart S, Roig A, Garcia O, Sastre R (2008) Organo-modified silica aerogels and implications for material hydrophobicity and mechanical properties. J Mater Chem 18 (2):207-213. doi:10.1039/b712553d

Mecklenburg M, Schuchardt A, Mishra YK, Kaps S, Adelung R, Lotnyk A, Kienle L, Schulte K (2012) Aerographite: Ultra Lightweight, Flexible Nanowall, Carbon Microtube Material with Outstanding Mechanical Performance. Adv Mater 24 (26):3486-3490. doi:10.1002/adma.201200491

Moner-Girona M, Roig A, Benito M, Molins E (2003) Aerogel thin film synthesis by a supercritical fluid-assisted sol-gel route in a single processing unit. J Mater Chem 13 (9):2066-2068. doi:10.1039/b307057c

Moner-Girona M, Roig A, Molins E, Martinez E, Esteve J (1999) Micromechanical properties of silica aerogels. Appl Phys Lett 75 (5):653-655. doi:10.1063/1.124471

Moore SW, Roca-Cusachs P, Sheetz MP (2010) Stretchy Proteins on Stretchy Substrates: The Important Elements of Integrin-Mediated Rigidity Sensing. Dev Cell 19 (2):194-206. doi:http://dx.doi.org/10.1016/j.devcel.2010.07.018

Murillo-Cremaes N, López-Periago AM, Saurina J, Roig A, Domingo C (2010) A clean and effective supercritical carbon dioxide method for the host-guest synthesis and encapsulation of photoactive molecules in nanoporous matrices. Green Chemistry 12 (12):2196. doi:10.1039/c004762g

Mwaikambo LY, Ansell MP (2001) The determination of porosity and cellulose content of plant fibers by density methods. J Mater Sci Lett 20 (23):2095-2096. doi:10.1023/a:1013703809964

Nata IF, Sureshkumar M, Lee C-K (2011) One-pot preparation of amine-rich magnetite/bacterial cellulose nanocomposite and its application for arsenate removal. RSC Advances 1 (4):625-631. doi:10.1039/c1ra00153a 
Pelham RJ, Wang Y-l (1997) Cell locomotion and focal adhesions are regulated by substrate flexibility. Proceedings of the National Academy of Sciences 94 (25):1366113665

Pinto RJB, Neves MrC, Neto CP, Trindade T (2012) Composites of Cellulose and Metal Nanoparticles, Nanocomposites - New Trends and Developments. Nanocomposites New Trends and Developments. InTech, September 27, 2012 under CC BY 3.0 license. doi:10.5772/50553

Ross P, Mayer R, Benziman M (1991 ) Cellulose biosynthesis and function in bacteria. Microbiol Rev 55 (1):35-58

Rowlands AS, George PA, Cooper-White JJ (2008) Directing osteogenic and myogenic differentiation of MSCs: interplay of stiffness and adhesive ligand presentation. American Journal of Physiology - Cell Physiology 295 (4):C1037-C1044. doi:10.1152/ajpcell.67.2008

Russler A, Wieland M, Bacher M, Henniges U, Miethe P, Liebner F, Potthast A, Rosenau T (2012) AKD-Modification of bacterial cellulose aerogels in supercritical CO2. Cellulose 19 (4):1337-1349

S. Hestrin MS (1954) Synthesis of Cellulose by Acetobacter xylinum. Biochem J 58:345-353

Sai H, Xing L, Xiang J, Cui L, Jiao J, Zhao C, Li Z, Li F (2013) Flexible aerogels based on an interpenetrating network of bacterial cellulose and silica by a non-supercritical drying process. Journal of Materials Chemistry A 1 (27):7963-7970. doi:10.1039/c3ta11198a

Saska S, Teixeira LN, de Oliveira PT, Gaspar AMM, Ribeiro SJL, Messaddeq Y, Marchetto $\mathrm{R}$ (2012) Bacterial cellulose-collagen nanocomposite for bone tissue engineering. J Mater Chem 22 (41):22102-22112. doi:10.1039/c2jm33762b

Schutz C, Sort J, Bacsik Z, Oliynyk V, Pellicer E, Fall A, Wagberg L, Berglund L, Bergstrom L, Salazar-Alvarez G (2012) Hard and Transparent Films Formed by NanocelluloseTiO2 Nanoparticle Hybrids. Plos One 7 (10). doi:10.1371/journal.pone.0045828

Segal L, Creely JJ, Martin AE, Conrad CM (1959) An Empirical Method for Estimating the Degree of Crystallinity of Native Cellulose Using the X-Ray Diffractometer. Textile Research Journal 29 (10):786-794. doi:10.1177/004051755902901003

Sehaqui H, Zhou Q, Ikkala O, Berglund LA (2011) Strong and Tough Cellulose Nanopaper with High Specific Surface Area and Porosity. Biomacromolecules 12 (10):3638-3644. doi:10.1021/bm2008907

Shezad O, Khan S, Khan T, Park JK (2010) Physicochemical and mechanical characterization of bacterial cellulose produced with an excellent productivity in static conditions using a simple fed-batch cultivation strategy. Carbohydr Polym 82 (1):173-180. doi:http://dx.doi.org/10.1016/j.carbpol.2010.04.052

Shi ZJ, Zhang Y, Phillips GO, Yang G (2014) Utilization of bacterial cellulose in food. Food Hydrocolloids 35:539-545. doi:10.1016/j.foodhyd.2013.07.012

Siro I, Plackett D (2010) Microfibrillated cellulose and new nanocomposite materials: a review. Cellulose 17 (3):459-494. doi:10.1007/s10570-010-9405-y

Sun CC (2005) True density of microcrystalline cellulose. J Pharm Sci 94 (10):2132-2134. doi:10.1002/jps.20459

Svensson A, Nicklasson E, Harrah T, Panilaitis B, Kaplan DL, Brittberg M, Gatenholm P (2005) Bacterial cellulose as a potential scaffold for tissue engineering of cartilage. Biomaterials 26 (4):419-431. doi:http://dx.doi.org/10.1016/j.biomaterials.2004.02.049

Ul-Islam M, Khan T, Park JK (2012a) Nanoreinforced bacterial cellulose-montmorillonite composites for biomedical applications. Carbohydr Polym 89 (4):1189-1197. doi:http://dx.doi.org/10.1016/j.carbpol.2012.03.093

Ul-Islam M, Khan T, Park JK (2012b) Water holding and release properties of bacterial cellulose obtained by in situ and ex situ modification. Carbohydr Polym 88 (2):596603. doi:10.1016/j.carbpol.2012.01.006 
Ul-Islam M, Shah N, Ha JH, Park JK (2011) Effect of chitosan penetration on physicochemical and mechanical properties of bacterial cellulose. Korean J Chem Eng 28 (8):1736-1743. doi:10.1007/s11814-011-0042-4

Ummartyotin S, Juntaro J, Sain M, Manuspiya H (2012) Development of transparent bacterial cellulose nanocomposite film as substrate for flexible organic light emitting diode (OLED) display. Ind Crop Prod 35 (1):92-97. doi:10.1016/j.indcrop.2011.06.025

Wang Y, Zhao Y, Deng Y (2008) Effect of enzymatic treatment on cotton fiber dissolution in $\mathrm{NaOH} /$ urea solution at cold temperature. Carbohydr Polym 72 (1):178-184

Wicklein B, Salazar-Alvarez G (2013) Functional hybrids based on biogenic nanofibrils and inorganic nanomaterials. Journal of Materials Chemistry A 1 (18):5469-5478. doi:10.1039/c3ta01690k

Wu Z-Y, Li C, Liang H-W, Chen J-F, Yu S-H (2013) Ultralight, Flexible, and Fire-Resistant Carbon Nanofiber Aerogels from Bacterial Cellulose. Angew Chem Int Ed 52 (10):2925-2929. doi:10.1002/anie.201209676

Yamada Y, Hoshino K, Ishikawa T (1997) The phylogeny of acetic acid bacteria based on the partial sequences of $16 \mathrm{~S}$ ribosomal RNA: the elevation of the subgenus Gluconoacetobacter to the generic level. Biosci, Biotechnol, Biochem 61 (8):12441251

Yano H, Sugiyama J, Nakagaito AN, Nogi M, Matsuura T, Hikita M, Handa K (2005) Optically transparent composites reinforced with networks of bacterial nanofibers. Adv Mater 17 (2):153-+. doi:10.1002/adma.200400597

Zhang L, Ruan D, Zhou J (2001) Structure and Properties of Regenerated Cellulose Films Prepared from Cotton Linters in NaOH/Urea Aqueous Solution. Industrial \& Engineering Chemistry Research 40 (25):5923-5928 
Figures and Tables

Figure 1. A) Picture of a BC layer on top of the bacteria culture liquid media. B) Cleaned BC films obtained after the NaOH treatment. C) Picture show a final BC film dried and the accordion setup were BC films are held during the drying process.

Figure 2. A) X-ray diffraction pattern for 1) BCE- room temperature, 2) freeze drying 3) supercritical drying and 4) non cleaned BCE film. B) FTIR spectra for a non-cleaned BCE film and a BCE film after cleaning.

Figure 3. SEM images of the BC films obtained after different drying conditions. Inserts show higher magnification images of the films.

Figure 4. A) Percentage of the water absorbed in the BC films after three wetting-drying cycles. B) Images of the BCE-SCD films and lens paper before and after wetting.

Figure 5. A) Optical image of the BCE-SCD film immersed in a petri dish with water. The red line on the Petri dish surface is clearly distinguishable. B) Uv-vis spectra of the papers before and after WAC in comparison to commercial papers.

Figure 6. Pictures of the bending test performed: A) BCE films before the bending test from the different drying methods, B) process of the bending test, $C$ ) the resulting shapes of the BC films after the test and D) the shape of the films obtained on a BCE film that was wetted-dried (WAC cycle).

Figure 7. A) Representative loading-unloading curve for each BC film obtained using the nanoindenter under a load of $0.4 \mathrm{mN}$. B) Mean values of Young Modulus (E) and 
702 Hardness (H) obtained for each BC film as a function of their density. (14 measurements

703 for each sample).

704

705 Figure 8. A) Schematic representation of the mechanical measurements performed over 706 two different directions. B) Load- displacement curves for BC films dried on SCD

707 conditions for the two bacterial strains.

708

709 Table 1. Summary of the structural and mechanical values obtained for the BC films.

710

711 Table 2 Values of "Young Modulus" (MPa) and penetration depth at $0.4 \mathrm{mN}(\boldsymbol{\mu m})$ from

712 BC films dried in SCD conditions measured in two directions of the BC films.

713

714 
715 Figure 1. A) Picture of a BC layer on top of the bacteria culture liquid media. B)

716 Cleaned BC films obtained after the $\mathrm{NaOH}$ treatment. C) Picture show a final BC film

717 dried and the accordion setup were BC films are held during the drying process.

718

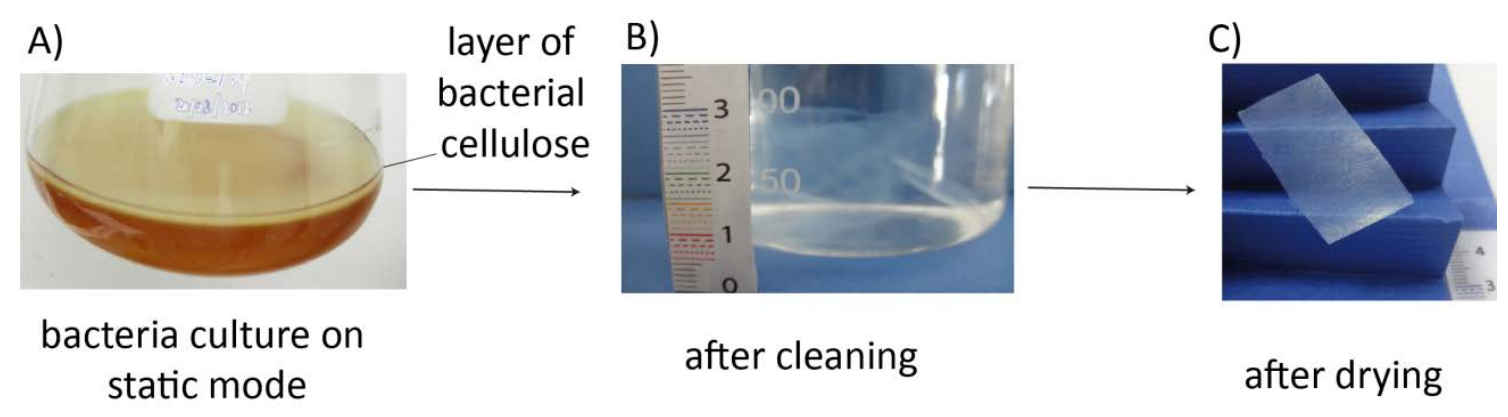

720

721 
722 Figure 2. A) X-ray diffraction pattern for 1) BCE- room temperature, 2) freeze drying 3)

723 supercritical drying and 4) non cleaned BCE film. B) FTIR spectra for a non-cleaned

724 BCE film and a BCE film after cleaning.

725
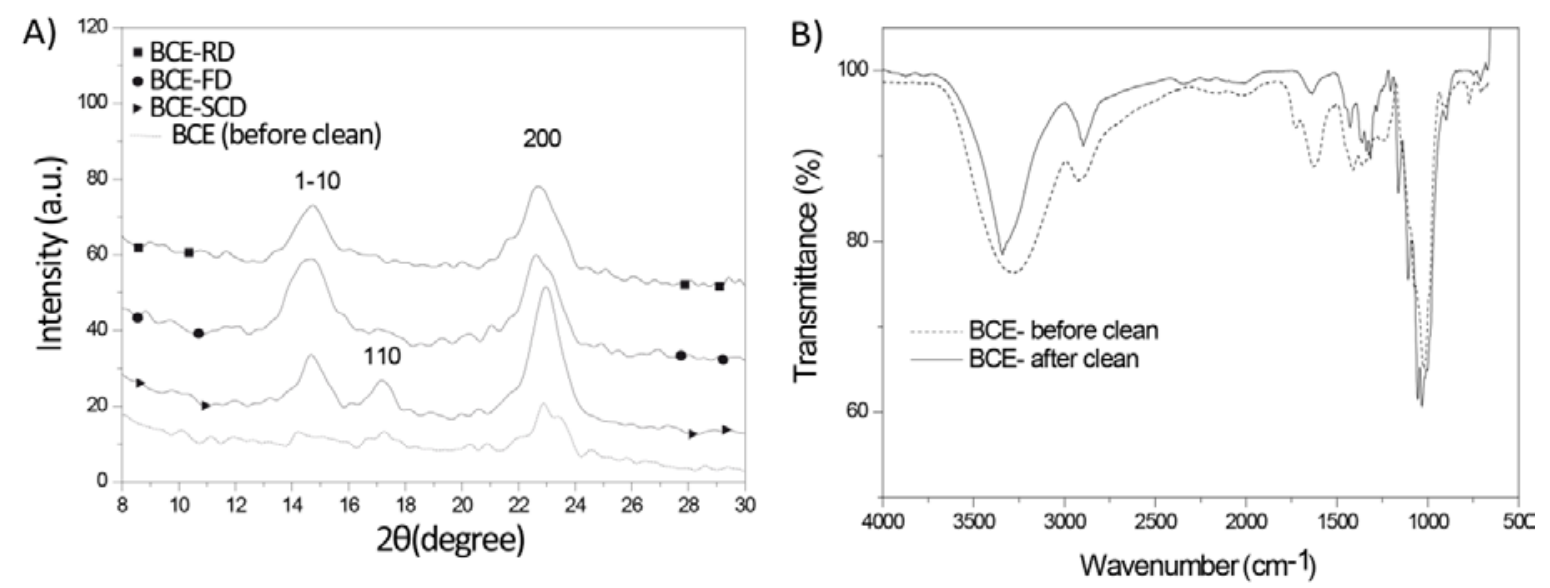

726 
727 Figure 3. SEM images of the BC films obtained after different drying conditions. Inserts 728 show higher magnification images of the films.
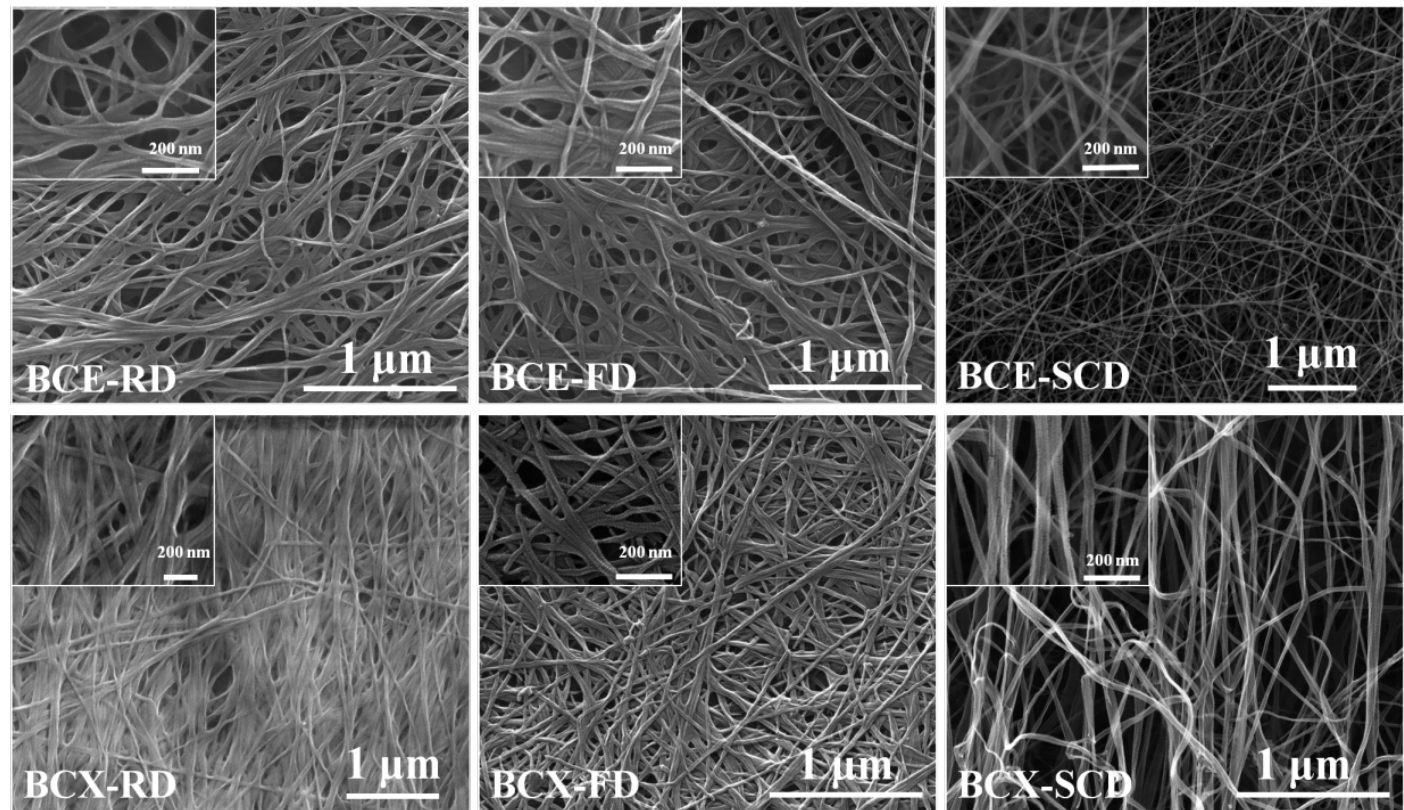

730 
731 Figure 4. A) Percentage of the water absorbed in the BC films after three wetting-drying

732 cycles. B) Images of the BCE-SCD films and lens paper before and after wetting.

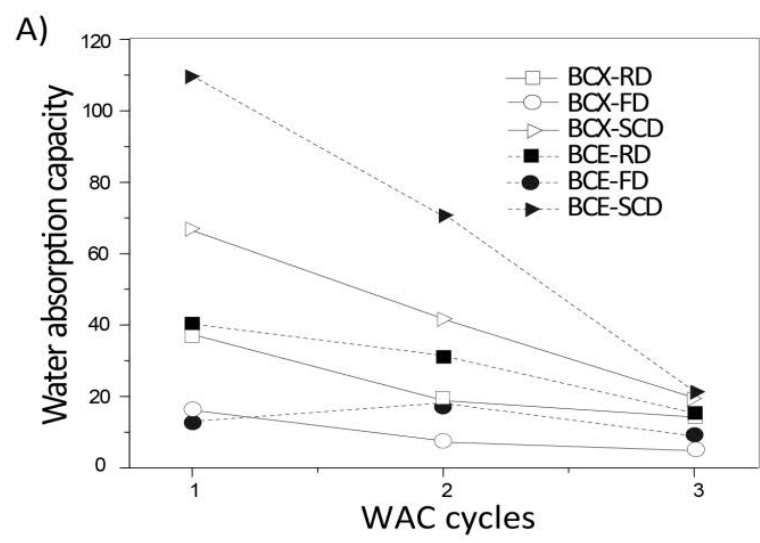

B) Before WAC

After WAC
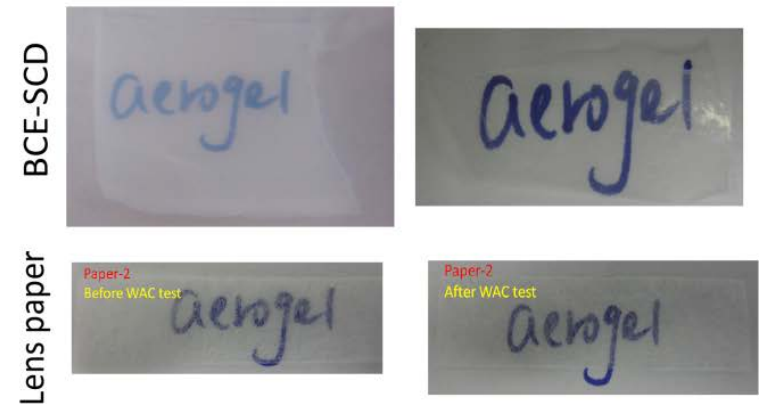

733

734 
735 Figure 5. A) Optical image of the BCE-SCD film immersed in a petri dish with water.

736 The red line on the Petri dish surface is clearly distinguishable. B) Uv-vis spectra of the 737 papers before and after WAC in comparison to commercial papers.

A)

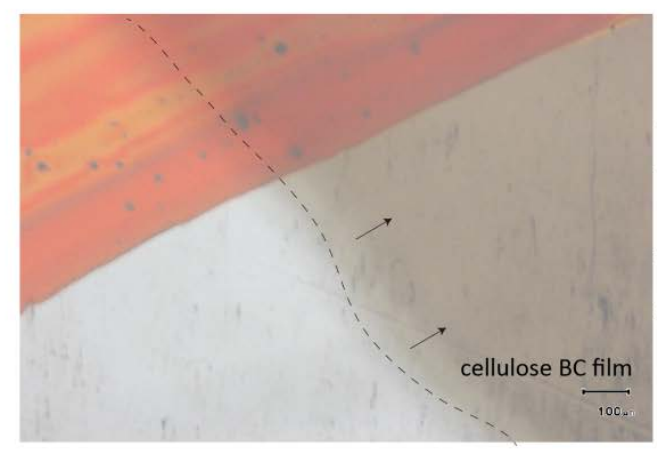

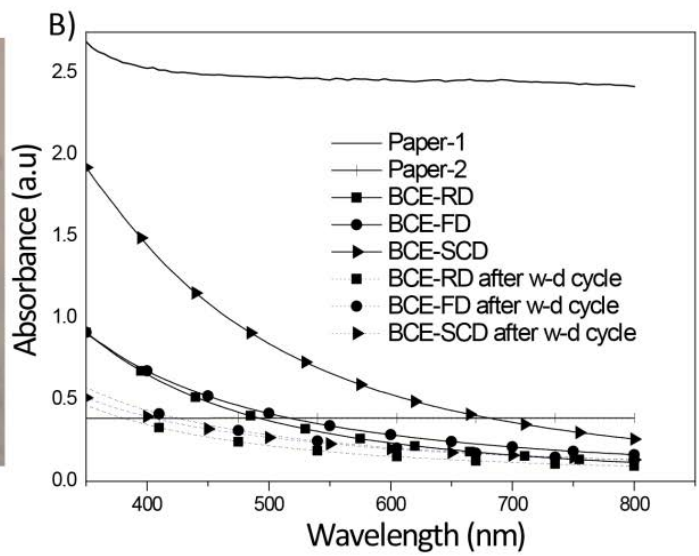

738 
740 Figure 6 shows pictures of the bending test performed: A) BCE films before the bending

741 test from the different drying methods, B) process of the bending test, $\mathrm{C}$ ) the resulting

742 shapes of the BC films after the test and D) the shape of the films obtained on a BCE

743 film that was wetted-dried (WAC cycle).

744

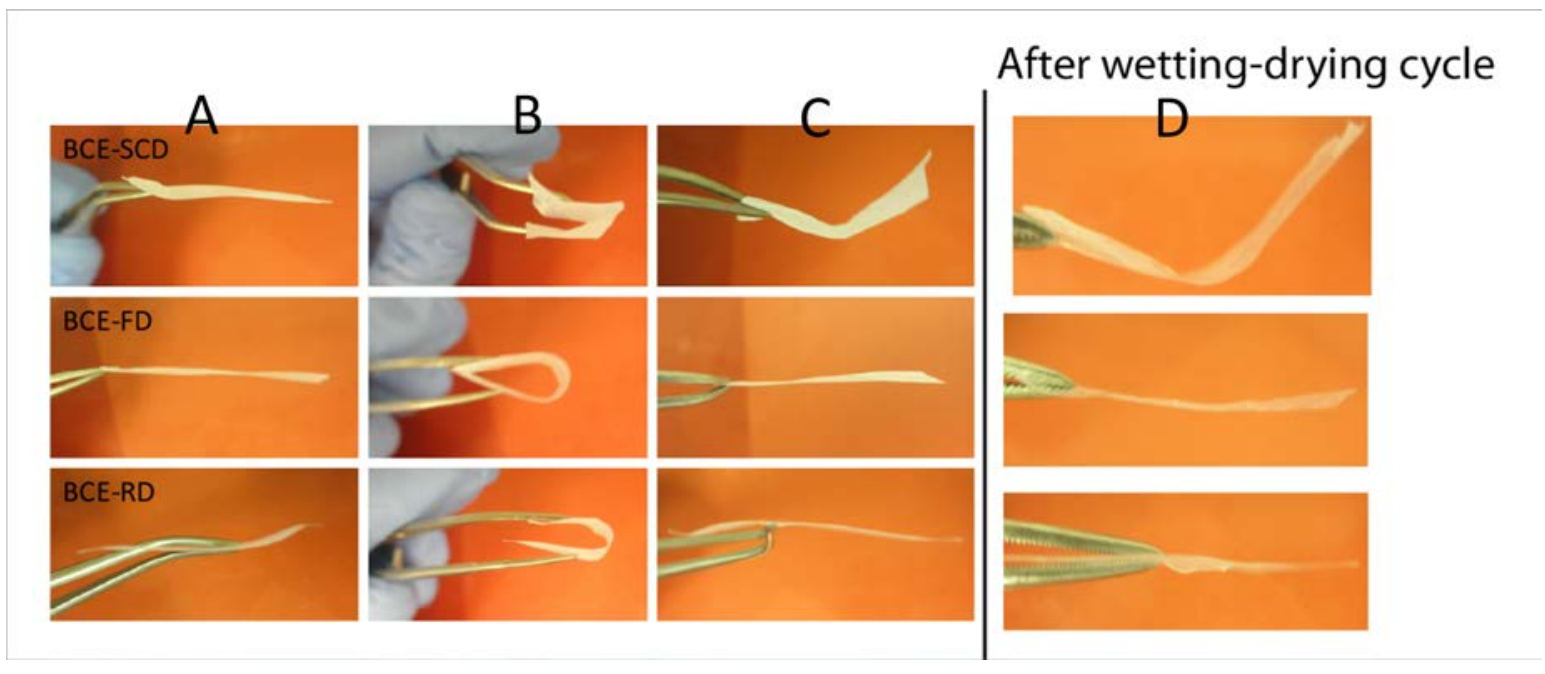


746 Figure 7. A) Representative loading-unloading curve for each BC film obtained using

747 the nanoindenter under a load of $0.4 \mathrm{mN}$. B) Mean values of "Young Modulus", ("H")

748 and Hardness (" $H ")$ obtained for each BC film as a function of their density (n=14). We

749 circled the" $E$ " and " $H$ " for BCE for clarity.
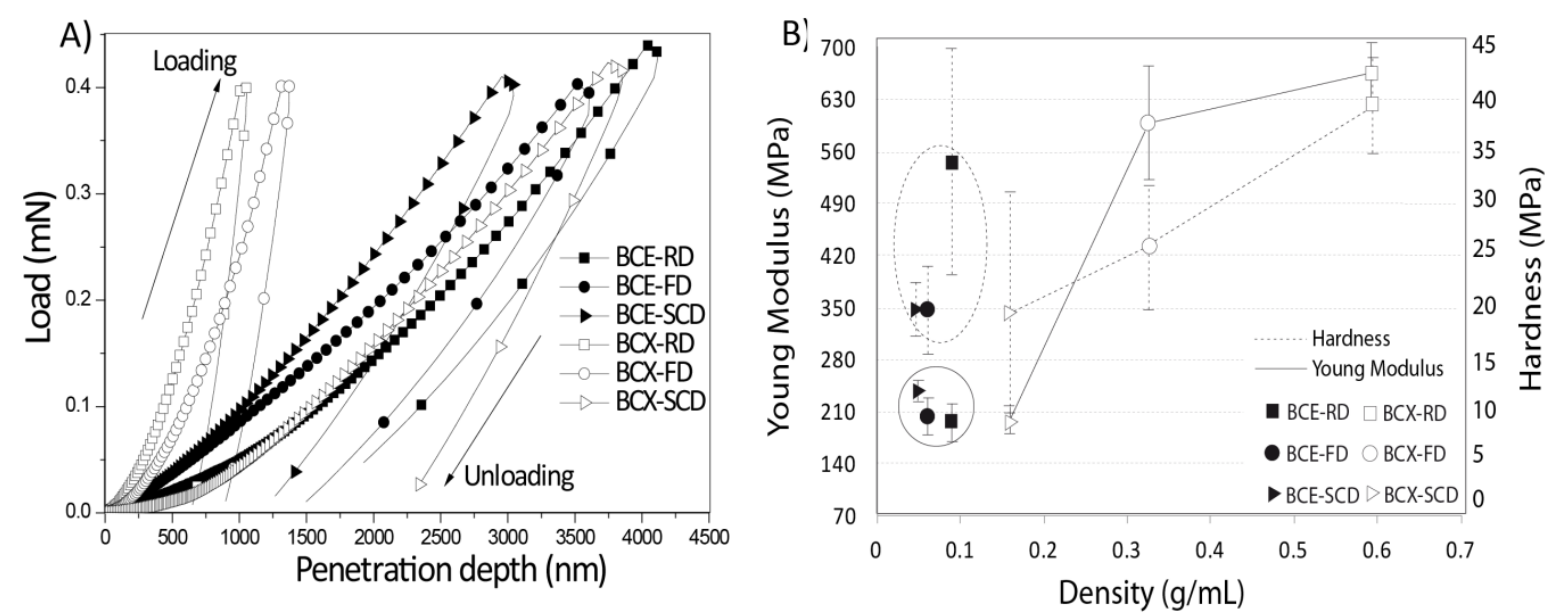

750 
752 Figure 8. A) Schematic representation of the mechanical measurements performed over

753 two different directions. B) Load- displacement curves for BC films dried on SCD

754 conditions for the two bacterial strains.

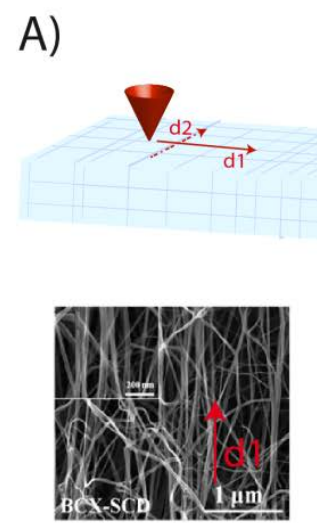

755

756

757

758

759
Penetration depth $(\mathrm{nm})$
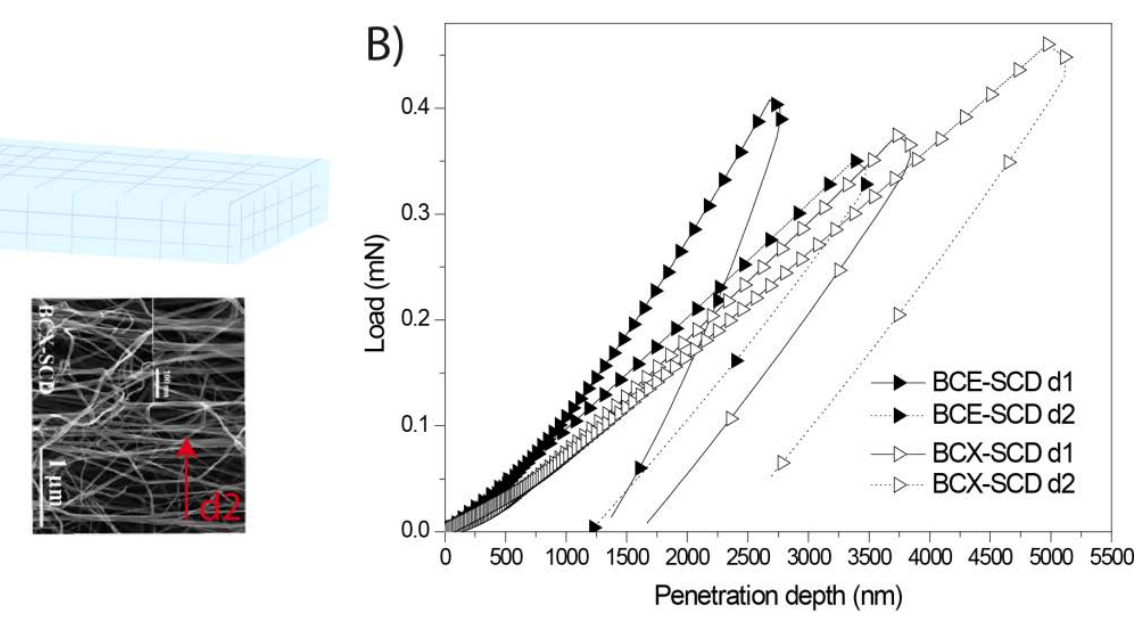
761 Table 1. Summary of the structural and mechanical values obtained for the BC films.

762

\begin{tabular}{|c|c|c|c|c|c|c|c|c|}
\hline & \multirow{2}{*}{\multicolumn{2}{|c|}{$\begin{array}{c}\text { Drying method } \\
\text { Strain }\end{array}$}} & \multicolumn{2}{|c|}{ RD } & \multicolumn{2}{|c|}{ FD } & \multicolumn{2}{|c|}{ SCD } \\
\hline & & & BCE & $B C X$ & BCE & $B C X$ & BCE & $B C X$ \\
\hline \multirow{7}{*}{ 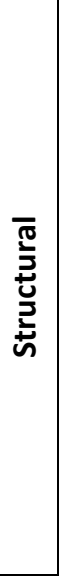 } & \multicolumn{2}{|c|}{$\begin{array}{c}\text { Film Thickness } \\
(\mu \mathrm{m})\end{array}$} & $24 \pm 2$ & $37 \pm 2$ & $34 \pm 2$ & $40 \pm 4$ & $58 \pm 3$ & $67 \pm 2$ \\
\hline & \multicolumn{2}{|c|}{ Density $(\mathrm{g} / \mathrm{mL})$} & $0.08 \pm 0.01$ & $0.59 \pm 0.03$ & $0.06 \pm 0.01$ & $0.32 \pm 0.02$ & $0.05 \pm 0.01$ & $\begin{array}{c}0.16 \pm \\
0.01\end{array}$ \\
\hline & \multicolumn{2}{|c|}{$\begin{array}{c}\text { Total Porosity } \\
(\%)\end{array}$} & $94 \pm 2$ & $60 \pm 2$ & $95 \pm 2$ & $79 \pm 2$ & $96 \pm 2$ & $89 \pm 2$ \\
\hline & \multicolumn{2}{|c|}{$\begin{array}{l}\text { Fibers diameter } \\
(\mathrm{nm})\end{array}$} & $17 \pm 2$ & $19 \pm 3$ & $20 \pm 4$ & $19 \pm 3$ & $16 \pm 2$ & $20 \pm 4$ \\
\hline & \multirow{3}{*}{$\sum_{3}^{4}$} & $1^{\text {st }}$ cycle & 39.5 & 37.3 & 15.8 & 15.8 & 109.4 & 66.6 \\
\hline & & $\begin{array}{l}\text { after } 3 \\
\text { cycles } \\
\end{array}$ & 15.3 & 14.2 & 92.3 & 50.2 & 19.8 & 19.4 \\
\hline & & \begin{tabular}{|c|} 
Decrease \\
$(\%)$
\end{tabular} & 61 & 62 & 42 & 68 & 82 & 71 \\
\hline \multirow{4}{*}{ 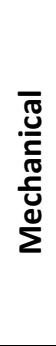 } & \multicolumn{2}{|c|}{$\begin{array}{c}\text { Penetration } \\
\text { depth at } 0.4 \mathrm{mN} \\
\text { load }(\mu \mathrm{m})\end{array}$} & $3.9 \pm 0.4$ & $1.1 \pm 0.1$ & $4.1 \pm 0.4$ & $1.4 \pm 0.3$ & $3.2 \pm 0.5$ & $\begin{array}{c}4.3 \pm \\
1.5\end{array}$ \\
\hline & \multicolumn{2}{|c|}{$\begin{array}{c}\text { Young modulus } \\
(\text { ("E")(MPa) }\end{array}$} & $198 \pm 46$ & $659 \pm 85$ & $204 \pm 46$ & $601 \pm 155$ & $238 \pm 25$ & $198 \pm 34$ \\
\hline & \multicolumn{2}{|c|}{$\begin{array}{c}\text { Hardness } \\
\left(“ H^{\prime \prime}\right)(M P a)\end{array}$} & $34 \pm 22$ & $39 \pm 9$ & $20 \pm 8$ & $26 \pm 12$ & $20 \pm 5$ & $19 \pm 21$ \\
\hline & \multicolumn{2}{|r|}{$E P(\%)$} & $59 \pm 7$ & $39 \pm 3$ & $53 \pm 4$ & $33 \pm 3$ & $52 \pm 5$ & $48 \pm 13$ \\
\hline
\end{tabular}

763 
765 Table 2 Values of "Young Modulus" (MPa) and penetration depth at $0.4 \mathrm{mN}(\boldsymbol{\mu m})$ from

766 BC films dried in SCD conditions measured in two directions of the BC films.

767

\begin{tabular}{|c|c|c|c|c|}
\cline { 2 - 5 } \multicolumn{1}{c|}{} & BCE-d1 & BCE-d2 & BCX-d1 & BCX-d2 \\
\hline $\begin{array}{c}\text { "Young modulus, E" } \\
M P a\end{array}$ & $233 \pm 50$ & $300 \pm 50$ & $150 \pm 40$ & $242 \pm 100$ \\
\hline $\begin{array}{c}\text { Penetration depth } \\
\text { at } 0.4 \mathrm{mN}(\mu \mathrm{m})\end{array}$ & $3.1 \pm 0.5$ & $3.5 \pm 0.9$ & $4.9 \pm 0.8$ & $4.4 \pm 0.7$ \\
\hline
\end{tabular}

768

769 
Supplementary Material
Click here to download Supplementary Material: Supporting Information Cellulose.pdf

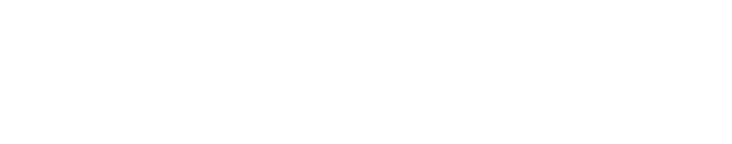

